\title{
Reaching truckers in Brazil with non-stigmatizing and effective HIV/STI services
}

Magda Chinaglia

Population Council

Sheri A. Lippman

Julie Pulerwitz

Maeve de Mello

Population Council

Rick Homan

See next page for additional authors

Follow this and additional works at: https://knowledgecommons.popcouncil.org/departments_sbsr-hiv

Part of the Demography, Population, and Ecology Commons, Health Policy Commons, Immune System Diseases Commons, International Public Health Commons, Medicine and Health Commons, Migration Studies Commons, Public Health Education and Promotion Commons, and the Virus Diseases Commons

How does access to this work benefit you? Let us know!

\section{Recommended Citation}

Chinaglia, Magda, Sheri A. Lippman, Julie Pulerwitz, Maeve de Mello, Rick Homan, and Juan Diaz. 2007. "Reaching truckers in Brazil with non-stigmatizing and effective HIV/STI services," Horizons Final Report. Washington, DC: Population Council.

This Report is brought to you for free and open access by the Population Council. 


\section{Authors}

Magda Chinaglia, Sheri A. Lippman, Julie Pulerwitz, Maeve de Mello, Rick Homan, and Juan Diaz 
Reaching Truckers in Brazil with Non-stigmatizing and Effective HIV/STI Services

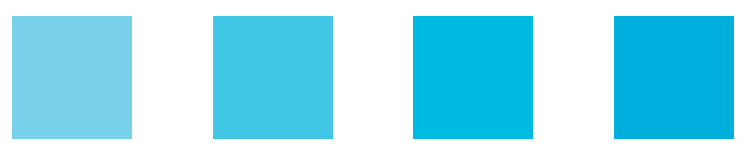

Population Council Horizons Program

PATH

Family Health International 


\title{
Reaching Truckers in Brazil with Non-stigmatizing and Effective HI V/ STI Services
}

\author{
Magda Chinaglia ${ }^{1}$, Sheri A. Lippman ${ }^{2}$, Julie Pulerwitz ${ }^{3}$, \\ Maeve de Mello ${ }^{1}$, Rick Homann ${ }^{4}$ J uan Díaz ${ }^{5}$
}

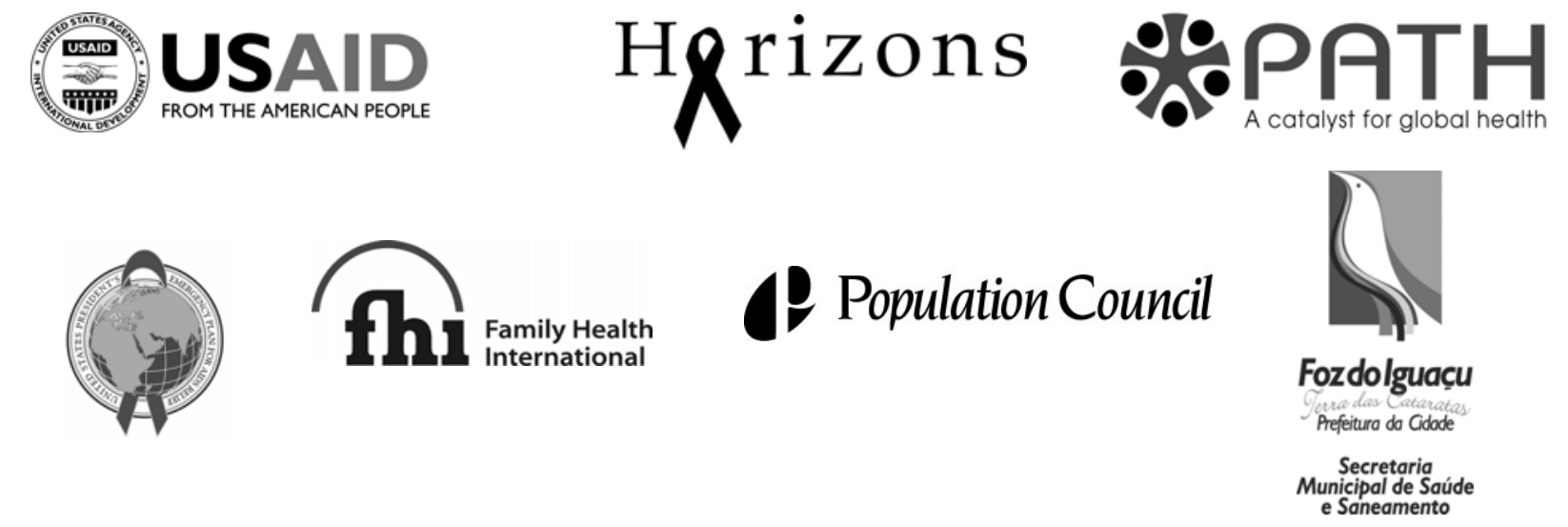

${ }^{1}$ Population Council, Brazil

${ }^{2}$ University of California, Berkeley, and Consultant for the Population Council, Brazil

${ }^{3}$ Horizons/PATH, Washington DC

${ }^{4}$ Family Health International

${ }^{5}$ Horizons/Population Council, Brazil 


\section{Acknowledgments}

The authors thank the study coordinator, Cristina Ogura, the project staff in Foz do Iguaçu (André Cyrillo, Anisséia Cotait, Cathia Vasconcelos, Daiane Fin, Elza Candido, Juan Talavera, Juliano Ferreira, Rosa Jeronymo, Rosana Freitas, and Valquiria Barbosa), and the field work supervisors in Uruguaiana: Silvia Pedroso, Ana Cristina da Silva, and Aline Quadros.

Many thanks to Annie Michaelis at the Horizons Program for her assistance with analysis and writing and to Elan Reuben at Family Health International (FHI) for his assistance with the analysis and writing of the costing section.

We also appreciate our numerous partners at the national, state, and municipal STI/AIDS Programs, including Rita Esmanhoto, Vera Zanetti, Thaís Aramburu, Patrícia Hoewell, and Ivo Brito, and our partners from collaborating institutions, including José Carlos Araújo, Mara Lúcia Cassilha de Oliveira, José Rodrigues de Matos, Rubens de Oliveira, and Guilherme Junqueira Franco. A special thanks to the customs officials at EADI Sul in Foz do Iguaçu and Uruguaiana, Hário Tieppo, Wanderlei Novakowski, and Antônio da Rocha.

Additional thanks to Population Council staff in Brazil, including Dário Silva, Lúcia Brito, Elizabeth Maciel, Maria Sílvia Setúbal, Silvana Muller, and Simone Rodrigues, and collaborators from Population Council New York, including Johannes van Dam, Heidi Jones, and Paul Hewett, as well as our intern, Andrea Lira. We thank Ricardo Díaz, Cecília Sucupira, Mário Janini, and Charlys Costa from the laboratory of retrovirology/EPM, as well as Dr. Arthur Reingold from the Division of Epidemiology at the University of California, Berkeley.

The authors are especially appreciative of the truck drivers who were willing to dedicate their time to participating in the study.

And finally, the authors would like to thank Jaime Rojas and Michael C. Burkly, from the USAID Mission in Brazil, for their support of the project.

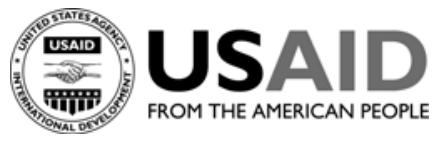

This study and final report were made possible by the President's Emergency Plan for AIDS Relief and the generous support of the American people through the United States Agency for International Development (USAID) under the terms of Cooperative Agreement No. HRN-A00-97-00012-00. The contents are the responsibility of the Horizons Program and do not necessarily reflect the views of USAID or the United States Government.

Published in May 2007.

\section{(P Population Council}

The Population Council is an international, non-profit, nongovernmental institution that seeks to improve the well-being and reproductive health of current and future generations around the world and to help achieve a humane, equitable, and sustainable balance between people and resources. The Council conducts biomedical, social science, and public health research and helps build research capacities in developing countries. Established in 1952, the Council is governed by an international board of trustees. Its New York headquarters supports a global network of regional and country offices.

Copyright (C) 2007. The Population Council Inc.

Suggested citation: Chinaglia, Magda, Sheri A. Lippman, Julie Pulerwitz, Maeve de Mello, Rick Homan, and Juan Díaz. 2007. "Reaching truckers in Brazil with non-stigmatizing and effective HIV/STI services," Horizons Final Report. Washington, DC: Population Council.

This document may be reproduced in whole or in part without permission of the Population Council provided full source citation is given and the reproduction is not for commercial purposes. 


\section{Table of Contents}

$\begin{array}{ll}\text { Executive Summary } & 1\end{array}$

$\begin{array}{ll}\text { Introduction } & 4\end{array}$

Mobile populations and the AIDS epidemic $\quad 4$

Study background $\quad 5$

$\begin{array}{lr}\text { Study goals and objectives } & 6\end{array}$

$\begin{array}{ll}\text { Methods } & 7\end{array}$

$\begin{array}{ll}\text { Site descriptions } & 7\end{array}$

$\begin{array}{ll}\text { Data collection } & 7\end{array}$

Key measures $\quad 9$

Data analysis $\quad 10$

Results from Formative Research $\quad 12$

$\begin{array}{ll}\text { Intervention Design and Content } & 14\end{array}$

$\begin{array}{ll}\text { Conceptual framework } & 14\end{array}$

Intervention activities $\quad 14$

$\begin{array}{ll}\text { Intervention Results } & 17\end{array}$

$\begin{array}{ll}\text { Study population profiles at baseline } & 17\end{array}$

Exposure to the intervention and service statistics $\quad 19$

$\begin{array}{ll}\text { Physical and psychosocial mobility } & 20\end{array}$

HIV-related stigma $\quad 21$

HIV testing: Quality of VCT and change in utilization over time 21

Partner communication about condom use and testing 23

$\begin{array}{ll}\text { Sexual risk behaviors } & 24\end{array}$

HIV/STI symptoms, prevalence, and treatment 26

Truckers’ perception of the intervention: Non-stigmatizing, accessible, and useful 27

Experience working in the customs station $\quad 29$

Additional benefits of the project $\quad 29$

$\begin{array}{ll}\text { Costs } & 31\end{array}$

$\begin{array}{ll}\text { Start-up } & 31\end{array}$

Service delivery $\quad 31$ 
Estimated annual cost of service delivery

Overall costs and costs per trucker reached

Estimated cost of replication

Discussion 34

References 



\section{Executive Summary}

Research with mobile populations has demonstrated that men in the mobile workforce tend to be exposed to greater HIV risk, and have higher sexually transmitted infection (STI) and HIV prevalence, than those in less mobile or non-mobile professions. Truck drivers, like other highly mobile groups, spend much of their time away from family and community, which increases the likelihood that they may engage in sexual risk behaviors and limits their access to stable health services or sustained exposure to public health messages.

At the request of the Brazilian Ministry of Health and with support from USAID/Brazil, Population Council conducted an assessment in 2001 in Brazilian border areas to determine which populations were most in need of HIV prevention activities. The research findings in the southern region revealed the presence of an extremely mobile, international truck driver community with little to no access to HIV prevention, testing, and treatment services.

In response to this need, Horizons/Population Council implemented an operations research study focused on trucker drivers (2002-2005) in the south of Brazil. In collaboration with the administration of the customs stations, municipal and state STI/AIDS programs, and Health Ministries, the investigators sought to examine the feasibility and impact of an HIV prevention project targeted to truckers crossing the southern border of Brazil.

\section{Methods and I ntervention}

The research team designed and implemented a quasi-experimental intervention study at customs stations in two similar border towns in Southern Brazil: Foz do Iguaçu (the intervention site) and Uruguaiana (the comparison site). To determine the best intervention strategy, the team conducted formative research with truckers from Brazil and neighboring countries, customs station staff, and key informants such as members of governmental AIDS programs, local NGOs, and sex workers. The resulting intervention, established in Foz do Iguaçu, consisted of a health post at the customs station providing voluntary counseling and testing (VCT) for HIV and STIs, syndromic management of STIs, as well as services to meet other health needs of truckers, such as testing for diabetes and blood pressure measurement. Intervention activities included outreach, education on HIV prevention, condom promotion, and free distribution of condoms and educational materials.

To assess program impact, cross-sectional data were collected from male truck drivers passing through the customs station in Foz do Iguaçu and compared with truckers going through customs in Uruguaiana (where intervention activities were not conducted), before and after the intervention. At baseline (AprilJuly 2003), a sample of 1,775 truckers (779 in Foz do Iguaçu and 996 in Uruguaiana) was interviewed. Follow-up interviews were conducted with 2,415 truckers (1,204 in Foz do Iguaçu and 1,211 in Uruguaiana), just after the intervention's end (April-June 2005). Truck drivers who participated in the VCT services responded to a brief questionnaire. In addition, qualitative interviews and focus group discussions (FGDs) were conducted prior to the intervention and at follow-up with a sub-sample of truckers who participated in the intervention as well as with others who did not. Surveys to determine satisfaction with the services were administered to all truckers who visited the health post, and service statistics were compiled. The costs of implementing the program were also tracked and are discussed in the report. 


\section{Hgrizons}

\section{Key Findings}

\section{Truckers were highly sensitive to societal prejudice against truck drivers as vectors of disease.}

During the formative research stage, truckers expressed concern that interventions advertised specifically as HIV programs for truck drivers would reinforce negative stereotypes about them as carriers of HIV and STIs. These findings helped inform the intervention design: rather than providing only services related to sexual health, it was determined that the intervention should provide HIV/STI testing alongside other health services that were of interest to truckers.

\section{At baseline, a sizable proportion of truck drivers in the study reported sexual risk behaviors.}

At baseline, 45 percent of all respondents reported having more than one sexual partner during the past six months. Reported condom use varied widely by type of partner; the majority reported consistent condom use during sex with commercial partners (85 percent), fewer reported consistent use with occasional partners, and almost no truckers reported consistent use with regular partners, such as their wives.

\section{Significant improvements were found in truckers' access to VCT after the intervention.}

At baseline, less than half of the respondents had ever had an HIV test, and respondents in the comparison site were more likely than those in the intervention site to have ever been tested. By follow-up, the opposite was true: the number of truckers who had ever had an HIV test increased by 49 percent in the intervention site and by only 15 percent in the comparison site $(\mathrm{p}<0.01)$. By the intervention's end, truckers in the intervention site were significantly more likely to have received an HIV test.

\section{Truckers responded positively to the intervention activities, and found them to be non- stigmatizing.}

There were originally a number of concerns expressed by truckers regarding the stigma associated with HIV. The holistic strategy of offering non-HIV-related services together with HIV/STI-related services was received very positively by truckers, and the majority of truckers reported that they found the project non-stigmatizing. Plus, many of the truckers seeking non-HIV related services ended up participating in HIV/STI educational discussions. Focus group discussions revealed that truckers appreciated the health post being located in the custom station, as it was easily accessible, as well as the quality of the services themselves. 


\section{Partner communication about condom use and HIV testing increased significantly among truckers passing through the intervention site.}

There was a significant increase $(\mathrm{p}<0.05)$ in reported communication about condoms with all types of sexual partners (occasional, commercial, and regular) in Foz do Iguaçu following the intervention; communication about condom use did not change in Uruguaiana in the two years between surveys. Similarly, more truckers in the intervention site reported discussing HIV testing with their partners, with the greatest percent change demonstrated in truckers speaking with their regular partners about testing. Communication around STIs improved significantly between truckers and their regular partners, again only in Foz do Iguaçu.

\section{Truckers surveyed in the intervention site reported a significant increase in condom use with occasional partners.}

Evidence of intervention impact was found in the sexual risk behavior that was determined prior to the study as most amenable to behavior change: condom use with occasional partners. Participants who reported ever using condoms with an occasional partner increased by 21 percent $(\mathrm{p}<0.05)$ in the intervention site while decreasing by 3 percent (non-significant change) in the comparison site at followup, compared with baseline. Condom use with sex workers was reportedly very high at baseline, and did not change much at follow-up; condom use with regular partners remained low.

\section{HIV prevalence among truckers was unexpectedly low.}

Only five of the 1,821 truckers tested for HIV were positive (0.3 percent), a prevalence comparable to that of the general population in Brazil. This unexpectedly low prevalence was corroborated by independently collected data from Uruguaiana, which found an HIV prevalence of 0.7 percent among truck drivers tested during 2001-2005. Prevalence of syphilis (active and past infection) among truckers tested in Foz do Iguaçu was also lower than expected at 4.4 percent.

\section{Conclusions}

The intervention strategy of placing a health unit inside the customs station and offering HIV/STI-related services with other services to meet the general health needs of truckers was successful for reaching truckers, was acceptable and well received, and promoted some important HIV-related behavior change. Nevertheless, given the low prevalence of HIV and moderate prevalence of STIs, truckers in southern Brazil may not be a priority population for HIV/STI-specific programming at this time. Truckers have various special health needs due to their mobility and should be reached with HIV prevention programs, however ensuring the provision of comprehensive health services to truckers would be a more appropriate intervention strategy. 


\section{Hgrizons}

\section{Introduction}

\section{Mobile Populations and the AI DS Epidemic}

Highly mobile populations such as transport workers, migrant laborers, and construction crews are key audiences for HIV prevention and treatment efforts but can be difficult to reach with traditional programs. Truck drivers, for example, spend much of their time on the road, where-away from family and community - they may be more likely to engage in sexual risk behaviors. Their mobility also makes it less likely that they will receive sustained prevention messages from public health campaigns, or that they will have regular access to stationary health and prevention services. The lack of a stable health service environment and the constant movement away from support networks complicate issues of continuity in care and of adherence to prevention and treatment activities for highly mobile groups.

A number of studies have demonstrated that men in the mobile workforce often have higher HIV prevalence than those in less mobile or non-mobile professions (Lagarde et al. 2003; Lurie et al. 2003; Lydie et al. 2004; Nunn et al. 1995; UNAIDS 1998). Truckers are perhaps the most studied mobile workforce population and have long been considered at increased risk of HIV and other STIs, with prevalence documented to be higher than those in other occupational groups or in the general population (Rakwar et al. 1999; Bwayo et al. 1994; Lacerda et al. 1997). While it is not mobility itself that makes truck drivers more vulnerable to HIV infection, mobile men have more opportunity and may be more ready to engage in casual sexual relationships while away from home.

Studies with truck drivers around the world indicate that many truckers have non-spousal or casual sexual partners while on the road (BEMFAM 2006; Bryan et al. 2001; Gibney et al. 2003; Malta et al. 2006; Morris et al. 1996; Podhisita et al. 1996; Rao et al. 1999; Singh et al. 1994). For example, in a random sample of 388 truck drivers in Bangladesh, respondents reported a mean of 4.6 sexual partners in the past year and 54 percent of respondents had relations with at least one commercial sex worker in that time; among sexually experienced truckers, only 31 percent had ever used a condom (Gibney et al. 2003). Studies in Brazil found that vaginal sex with casual partners was reported by one third (Villarinho et al. 2002) to one half (Lacerda et al. 1997) of surveyed truck drivers, respectively involved in short $(<50 \mathrm{~km})$ and long trips, with only around 60 percent of respondents using condoms with these partners (Lacerda et al. 1997; Villarinho et al. 2002). In addition to these reported risk behaviors, HIV and STI rates were relatively high among Brazilian truckers: 13 percent tested positive for syphilis, 8 percent tested positive for active syphilis infection, and 1.3 percent tested positive for HIV (Lacerda et al. 1997), as compared to the national syphilis and HIV estimates of 1.1 to 1.7 percent and 0.42 to 0.65 percent, respectively (Salles et al. 2003; Rodrigues et al. 2004; Ministry of Health 2001).

There are multiple reasons that could explain this increased risk among truckers. As a 2001 UNAIDS report summarizes, mobile populations face various situations and stresses while traveling that lead to increased health risks, including exposure to HIV/STIs (UNAIDS 2001). As repeatedly reported, higher rates of casual sexual partnerships on the road are common. The willingness to engage in sexual partnerships may be due to increased opportunities to engage in casual sex, but is likely also due to the absence of family and social networks that reinforce sexual norms of monogamy. When norms that typically influence behaviors are removed, individuals may experience a state that sociologists refer to as "liminality," during which people who are passing between different environments feel outside the norms and networks of each and may engage in behaviors that they would not otherwise (e.g., Thomas 2005). Because mobile populations may also have less access to health care and public prevention messages, the 
liminal state with fewer structured norms is reinforced. Finally, additional structural stressors surrounding mobile workforce professions include issues of safety while traveling: truckers report experiencing theft, violent crime, and long work hours. Such stressors create a social context of anxiety and instability that can reinforce vulnerabilities (Stratford et al. 2000).

Also contributing to truckers' vulnerability to HIV is the stigma related to the AIDS epidemic, as populations who experience stigma and discrimination often fear being associated with the disease. Since the early days of the AIDS epidemic, stigma and discrimination have been recognized as obstacles to the adoption of preventive measures by individuals as well as to successful prevention and care programs. For example, various qualitative studies have supported the hypothesis that high levels of perceived stigma and discrimination influence individuals' decisions to access testing and treatment services for HIV (Bharat et al. 2001; McGrath and Ankrah 1993; Plummer et al. 2006). However, it has been difficult to measure the complex concept of HIV-related stigma and to quantitatively confirm the relationship between stigma and service utilization (Nyblade 2006). Furthermore, stigma and discrimination operates not only by discouraging service utilization, but is compounded when a marginalized group experiences stigma, such as when truck drivers are often framed as vectors of HIV. Limited or no information is available regarding the quantitative relationship between stigma, truck driving, and voluntary counseling and testing (VCT) uptake in Latin America.

\section{Study Background}

Concerned about insufficient HIV services and a growing number of HIV infections in mobile populations around the borders of Brazil, the Ministry of Health proposed a partnership with Population Council Brazil in 2001 to perform an assessment of HIV risk in Brazilian border regions. With support from the USAID Mission, the research team carried out an assessment of available services and cultural contexts shaping the HIV epidemic in six frontier municipalities (for full results see Diaz et al. 2003; Lippman et al. 2007). Two southern municipalities were visited: Foz do Iguaçu, which shares a tricountry border with Argentina and Paraguay, and Uruguaiana, which shares a border with Argentina and is in close proximity to the Uruguay border. The assessment findings in the south revealed the presence of an extremely mobile community with little or no access to HIV prevention, testing, and treatment services: truck drivers. The assessment also confirmed that Brazilian, Argentine, Chilean, Paraguayan, and Uruguayan truckers had easy access to commercial sex and extremely limited access to health services, condoms, education, and prevention messages. Assessment findings suggested that the most appropriate strategy to bring prevention and care to truck drivers was to implement targeted prevention activities inside customs stations, where truckers remained parked for anywhere from one day to a week while waiting for documents and cargo to clear customs.

Horizons/Population Council then implemented an operations research study focused on truck drivers (2002-2005), in collaboration with the Foz do Iguaçu Municipal Secretariat of Health, the Paraná State Secretariat of Health, the Uruguaiana Municipal STI/AIDS Program, and the customs station in Foz do Iguaçu (EADI Sul). Funding was provided by USAID/Brazil and USAID/Washington, with additional support for condoms and HIV/STI tests from the Foz do Iguaçu Municipal Secretariat of Health, and for educational materials from DKT and GoodYear Tires. The project examined the feasibility and impact of an HIV prevention project targeted to truckers crossing the southern border of Brazil. The intervention included diverse HIV/STI prevention activities, VCT for HIV and syphilis, and general health services. 


\section{Hgrizons}

\section{Study Goals and Objectives}

The goal of this operations research was to determine how best to meet the HIV/STI prevention and care needs of truck drivers. The underlying assumption was that an integrated or holistic approach to health care was vital in light of their special circumstances.

The main objectives of the research project were to:

- Document the main psychosocial and environmental factors that contribute to HIV/STI risk behaviors among truckers.

- Decrease HIV/STI risk behaviors among truckers through a targeted, multi-level intervention.

- Promote HIV counseling and testing and STI diagnosis among truckers, and provide a point of entry into the treatment system for those who were HIV-positive or had an STI. 


\section{Methods}

\section{Site Descriptions}

Foz do Iguaçu, a municipality of over 300,000 residents in the southern region of Brazil, shares a tricountry border with Argentina and Paraguay. The population is growing rapidly in a concentrated urban area; the annual population growth at the time of project implementation (4 percent) was double that of regional growth, likely due to the lucrative tourism industry and intense illegal commercial activity. In 2004, approximately 250 trucks crossed the Paraguayan and Argentinean borders every day. During the evaluation phase, trucks remained parked at the local custom station for an average of 31 hours while the drivers waited for documents and cargos to clear customs.

Uruguaiana, bordering Argentina and sitting approximately 60 kilometers from Uruguay in the extreme southwest of Brazil, has approximately 135,000 inhabitants and is home to the busiest land border in South America. The local economy is dominated by seasonal agriculture and farming. At the time of project implementation, Uruguaiana had suffered some economic setbacks following closure of textile production facilities and downsizing of the local rice and meat industries, resulting in increasing unemployment and squatter settlements. In 2004, approximately 460 truckers entered the local customs station daily. During the project evaluation, trucks remained parked for an average of 29 hours.

\section{Data Collection}

The intervention was evaluated using a quasi-experimental study design with pre- and post-test surveys: cross-sectional data were collected from truckers entering the customs station in Foz do Iguaçu and compared with truckers entering the customs station in a similar border town (Uruguaiana) before and after the intervention. Baseline and follow up data were collected from April to July 2003 and from April to June 2005, respectively. Interviews were conducted with 1,775 truckers (779 in Foz do Iguaçu and 996 in Uruguaiana) before the intervention and 2,415 truckers (1,204 in Foz do Iguaçu and 1,211 in Uruguaiana) just after its end. Truckers entering the customs stations were recruited systematically, so that truckers had a fixed probability of being selected to participate. Field staff sought those who did not present for interviews up to seven times.

5,363 eligible truck drivers were invited to participate in the first cross-sectional survey, of which the study team was unable to contact 56 percent in Foz do Iguaçu and 58 percent in Uruguaiana. A number of these truckers likely moved through customs too quickly to be located, especially those carrying soy and other perishable goods. Of the 2,307 eligible truck drivers who were contacted successfully, 77 percent agreed to be interviewed, 5 percent had incomplete data regarding the reason for non-interview, and 18 percent refused for documented reasons including: no time (51 percent), no interest (39 percent), discomfort with survey content (5 percent), and length of interview (3 percent). The proportions of refusals were not statistically different between Brazilian Portuguese-speaking and non-Brazilian Spanish-speaking truckers.

At the follow-up survey, of the 5,519 eligible truckers invited to participate, the study team was able to successfully contact 47 percent in Foz do Iguaçu and 41 percent in Uruguaiana. Of the 2,393 truckers contacted, 87 percent agreed to be interviewed, 3 percent had incomplete data on the reasons for not taking part in the study, and 10 percent refused to be interviewed. Reasons for refusal included not having 


\section{Hgrizons}

the time to be interviewed (74 percent), no interest (16 percent), discomfort with survey content (4 percent), length of interview (1 percent), and other reasons (5 percent).

The majority of interviewers were students recruited from local universities. In Uruguaiana some municipal outreach workers were also selected. Between 12 and 18 trained interviewers of both sexes performed the interviews. Approximately one third of them were bilingual (Portuguese/Spanish). Prior to baseline and follow-up data collection, interviewers received 40 hours of theoretical training on HIV/AIDS/STIs, research methods and ethical aspects of research, and interviewing techniques. They were also introduced to the study protocol and trained on the use of the data collection and quality control instruments through role-playing and pilot administration with volunteer truckers.

The face-to-face survey at baseline and follow-up covered a wide variety of topics including information on sociodemographic characteristics, occupation and mobility, sexual behaviors (with principal, occasional, and commercial sex partners), sexual health and STI history, opinions about condom use, HIV testing history, knowledge about HIV and AIDS, stigma towards people living with HIV, and exposure to HIV/AIDS/STIs interventions. Both baseline and follow-up surveys were pre-tested with truckers and adapted for flow and language in Spanish and Portuguese with back translation into English.

Selected truckers were approached by the interviewers, who administered an eligibility form to ensure that they had not already participated in the current round of interviews. Eligible truckers who gave written, informed consent in the language of their choice were invited to be interviewed in either Spanish or Portuguese in a private room within the customs station or at a private outdoor spot. Interviews lasted, on average, 38 minutes at baseline and 30 minutes at follow-up. Those who participated in the follow-up survey received a t-shirt printed with the project logo.

Quantitative data were triangulated with other sources of information. In addition to qualitative data collected during the formative research conducted in 2002 to inform the intervention (see details below), qualitative data were collected in Foz do Iguaçu at the end of the intervention. Participants were purposefully recruited for participation in qualitative research to include truckers who utilized VCT services as well as those who did not utilize VCT services, and to ensure inclusion of truckers from different home countries. Evaluative qualitative data included six focus group discussions (FGDs) and one in-depth-interview (IDI) with users and three FGDs and three IDIs with non-users, for a total of 49 respondents, including Brazilian, Paraguayan, Argentine, and Chilean truckers. Two FGDs and an IDI were also conducted with 10 local sex workers. Convenience samples were used to recruit participants for the FGDs and IDIs.

In addition, consenting truckers who visited the VCT unit between October 2004 and March 2005 were administered a survey that focused on risk behaviors, service utilization history, and quality of services (n $=1,945$ ). Consenting truckers gave blood for HIV and syphilis testing, for which treatment was provided if indicated. Most truckers accessing the VCT unit $(n=1,469)$ also provided a second blood sample for future STI testing. A nested study was then conducted to estimate the prevalence of Herpes Simplex Virus type-2 and Hepatitis B among a sample of the population $(n=799)$, including truckers testing positive for HIV or syphilis, or with a syndromic diagnosis (115) as well as 684 randomly selected HIV/syphilisnegative truckers. Participants were informed that future testing would be performed anonymously and that they would not receive the test results. All tests were performed at the Virology Laboratory at the Escola Paulista de Medicina. 
Program staff also monitored intervention activities and tracked service statistics. A costing analysis was conducted using customized data reporting forms, which were designed to help program staff document their activities and systematically record and classify expenses related to these activities. All study procedures were pilot-tested and modified as necessary. Approval for the study was obtained from Population Council's Internal Review Board and from the Committee for the Protection of Human Subjects at the Universidade Estadual do Oeste do Paraná (UNIOESTE), in Cascavel, Brazil. A monitoring visit was conducted by an outside auditor (Dr. Arthur Reingold, University of California, Berkeley) during the intervention phase of the study to ensure adherence to protocol.

\section{Key Measures}

Several key measures served as the basis for analyses of the truckers' potential risk at baseline and of the intervention's impact. Of particular interest, multiple measures of mobility were included, both physical and psychosocial. Physical mobility was measured using three questions: 1) average length of trips away from home, 2) nights spent at home during the past four weeks, and 3) months spent at home in the past year. The psychosocial component of mobility, or liminality, which refers to moving between spaces, was measured to inform the effect that traveling may have on the participants and their behaviors. To determine how the liminal environment might influence behavior, a 10-item index about feelings related to being on the road and behaviors while traveling was created. Participants were asked to agree, partially agree, or disagree with statements such as: "I feel like I am a different person when I am on the road;" "When I am on the road I can do things that I don't do at home;" or "I think that I'm more likely to have casual sex when I'm on the road than when I'm at home.”

HIV-related stigma at baseline was also measured quantitatively. The survey included fifteen questions on HIV-related stigma, based on a literature review and formative research in Brazil. These items were intended to represent several conceptual domains of stigma and discrimination: fear of casual transmission, blame toward people living with HIV/AIDS, and fear of enacted stigma (discrimination) from others if one were to contract HIV or be suspected of having HIV or AIDS. The items were formatted as statements with which participants were asked to agree, partially agree, or disagree.

Key variables for measuring behavior change, collected before the intervention began and after intervention activities were concluded, focused on both sexual risk behaviors as well as the more proximal marker of HIV-related communication with sexual partners. Truckers were asked whether they had had sex with principal, occasional, or commercial partners during the past six months. Principal partners were defined as "a wife, steady girlfriend or boyfriend, or someone that you live with;" commercial partners were defined as "those with whom you have sex in exchange for money or gifts;" and occasional partners were defined as "those that you see sporadically or saw only once that you do/did not pay for sex.” Questions about sexual partnerships referred to the six months prior to the interview and included questions about communication as well as frequency of condom use (always, most of the time, sometimes, rarely, or never). From these questions, it was possible to examine consistent condom use (those responding “always”) and "ever” condom use (any response except "never”). The total number of any partners during the past month and numbers of occasional and commercial partners in the past six months were also reported.

In addition, the utilization of services offered at the trailer, including HIV testing services, was measured. In the survey, participants were asked: "Have you ever been tested for HIV?" and "Do you know where you can get an HIV test free of charge?” Those who were tested were also asked about whether they had 


\section{Hgrizons}

received pre- and post-test counseling. Satisfaction with services was assessed through the survey administered to truckers visiting the trailer and through qualitative evaluation, when users were asked what they liked or disliked about the services.

The cost analysis assessed the cost of resources paid for from project funds and also included the value of donated or reallocated resources where no financial payment was incurred, since these resources would need to be acquired if the intervention were to be replicated. Therefore, the resulting number representing the cost of resources is greater than the funds actually spent.

Results are presented separately for start-up costs and service delivery costs. The analysis focuses on the value of resources used over a 32-month period (August 2002 - March 2005), from the start-up period (14 months) through the service delivery phase (18 months). This excludes expenses used in the eight-month planning phase (including preparation of the project; ethical committee approvals; negotiation with the $\mathrm{MOH}$, Secretary of Health, and the administration of the customs area) and expenses related only with research, not needed for the services offered to truckers. Also excluded are the resources used for research (e.g. monitoring of data processing) that are not related to the intervention. The exchange rate of 1 US Dollar = 3.06808 Brazilian Reais (the historical average for the period of August 2002-March 2005) was used in the analyses (see Appendix 1 for complete cost details).

\section{Data Analysis}

Data analysis was completed with STATA statistical software (baseline analysis with version 8.2 and evaluation with both 8.2 and 9.2). A comparison was made of truckers' key sociodemographic characteristics, mobility, sexual behavior, and condom use at baseline between the two cities using chisquare and Mann-Whitney tests. Logistic regression was used to analyze the relationship between mobility measures and reports of sexual partnerships in the past six months, and negative binomial regression was used to analyze the association of mobility measures and the number of commercial sexual partners reported. Cluster analysis was used to categorize respondents into three liminal groupings based on their responses to the scale items. Each cluster included truckers who shared dispositions or feelings about life on the road.

To evaluate the project, researchers conducted descriptive analyses, chi-squared tests, and multivariate logistic regression, comparing covariates and key outcomes (condom use, communication, and HIV testing utilization) at baseline and follow-up. Univariate analyses were conducted to describe the population characteristics by city and time point, as well as to describe the prevalence of reported behaviors. To determine whether the intervention had an impact, proportions of truckers reporting HIV protective behaviors in the intervention site were compared to truck drivers in the comparison site, and percent change in report of behaviors from baseline to follow-up survey was assessed using multivariate analyses. For example, to assess whether the proportion of truckers in the intervention community who reported always using condoms increased by a greater margin than that in the comparison community, a logistic model for condom use was used, with an indicator for city, time, and intervention exposure (using an interaction term for city and time).

Turning to biological markers, serum samples were tested for antibodies against HIV types 1 and/or 2 (HIV-1 and HIV-2), using an enzyme-linked immunosorbent assay (ELISA). The presence of anti-HIV antibodies was confirmed in samples with a positive ELISA using indirect immunofluorescence assay (IFI), following the Brazilian AIDS Program algorithm for HIV diagnosis. Seroprevalence for syphilis 
was determined by a commercial antibody to cardiolipin test (VDRL) and by a fluorescent treponemal antibody absorption test (FTA-ABS). All positive samples for VDRL and FTA-ABS were classified as positive for syphilis (including recent or past infection). A selection of truckers was tested for hepatitis B and HSV-2 following the project. Hepatitis B testing consisted of two phases. The first test performed was a qualitative immunoenzyme assay (ELISA anti-HBc total), which indicated whether the participant had ever been exposed to the virus. If negative, the participant was classified as hepatitis B negative. If the anti-HBc test was positive, an enzyme-linked immunosorbent assay for surface antigen (ELISA HBsAg) was performed in order to determine whether the participant had only antibodies to the virus (immune) or an active infection, although the diagnosis did not differentiate between acute and chronic infections. HSV-2 testing was carried out using a type specific ELISA test for detection of IgG antibodies to HSV type 2 to detect both latent and active infections. 


\section{Hgrizons}

\section{Results from Formative Research}

Formative research was carried out in August 2002 to help design the intervention. The formative research included 5 FGDs and 15 IDIs with truck drivers, 3 FGDs and 6 IDIs with sex workers, and 1 FGD with customs officials in Foz do Iguaçu. All interviewed truck drivers were asked to complete a mapping exercise as well as a brief self-administered KAP questionnaire (designed by DKT, who later provided condoms for the intervention.) In addition, key informant interviews were conducted with one manager at each of three organizations serving truck drivers: a transport company, a social services agency and health center for transport laborers, and the customs station. Research was conducted in two languages: Portuguese with the Brazilian population and Spanish with truckers from other countries in Latin America (including Paraguay, Argentina, and Chile).

Analysis of the discussions and interviews revealed that truckers were reluctant to leave their vehicles, for a variety of reasons, including concerns about safety and burglary. The trucks were often required to remain in the customs area for two to three days until documentation was completed, and were typically not permitted to enter the local urban area. These findings indicated that truck drivers would have difficulty accessing services outside of the customs area, and that offering health services, including HIV prevention services, within the customs station could be an important strategy.

It was also observed that while condoms were not easily available at the customs area, there was a booming commercial sex area directly in front of the station. One trucker stated:

...the women [sex workers] stay near the customs station...because it's where a lot of truckers come; wherever you have truckers, you have sex workers.

IDI, Brazilian trucker

...normally the guys [truckers] buy condoms. I also buy them... I don't know if the city supplies condoms here in Foz do Iguaçu, but if there were a health post here inside [of the customs station] that would be ideal for condom distribution.

IDI, Brazilian trucker

Most truckers reported having permanent partners or wives, and a complex network of sexual and social relationships while traveling, including paid sex (commercial); friends or acquaintances with whom they have occasional sex, usually involving favors and/or gifts; and the maintenance of permanent girlfriends (sometimes in more than one city).

... I don't buy sex... I've always had a girlfriend and she's never said "let's go have sex, but you need to pay me." No, we met and became friends and started to see each other ... but I help her in other ways, I mean, independently of whether she would charge me or not ... I give her money to help with her expenses.

FGD, Chilean trucker

Some truckers also reported traveling occasionally with their wives or girlfriends. Given the diversity of sexual partnerships, it was deemed important to focus on condom use promotion with all sexual partners, though truckers indicated that proposing condom use with their wives was very difficult. One trucker pointed out: 
...if a man suddenly begins using condoms, I think that his partner won't trust him ever again, because why would he start using condoms now; he'd need a convincing explanation....

IDI, Brazilian trucker

Thus, the intervention strategy was to promote condom use with all partners, but particularly with occasional or casual partners.

The interviewed truckers were also highly sensitized to societal prejudice against members of their profession as vectors of disease. Truckers shared:

...they implement campaigns for and about truckers as if truckers were the cause [of the AIDS epidemic]....

IDI, Brazilian trucker

...the issue is that now in Brazil, we are seen as the transmitters of HIV... .

FGD, Brazilian trucker

Some participants also asserted that interventions advertised specifically as HIV/AIDS programs for truck drivers would only reinforce negative stereotypes. The truckers' fears of being blamed as vectors of disease led to careful consideration of the methods for service delivery. Rather than providing only services related to sexual health, it was determined that the intervention should provide HIV/STI testing alongside a variety of health services that were of interest to truckers. They would be provided all in one locale and would not be advertised solely as HIV/STI services, to avoid labeling clients as potential vectors of HIV/STIs. Truckers also agreed that this would be a good strategy:

...if the [planned] health post offered a wide range of services it would be easier to increase awareness about diseases... to be aware of HIV, syphilis, and all types of sexual diseases... and also include general diseases... .

IDI, Brazilian trucker 


\section{Hgrizons}

\section{Intervention Design and Content}

\section{Conceptual Framework}

In addition to the formative research findings, the intervention design was based on a conceptual and theoretical framework. The intervention drew upon the Ecological Model (McLeroy et al. 1988) for its holistic perspective emphasizing the multiple sources of vulnerability facing truckers. As such, the intervention was designed to engage truckers on an individual level, an interpersonal level, and a broader community or structural level. At a structural or environmental level, the intervention increased access to services by creating healthcare infrastructure in a location that is convenient for the truckers' mobile lifestyles. At an interpersonal level, messages aimed to increase communication about condom use between truckers and their partners. At an individual level, individualized counseling and educational messages were meant to contribute to behavior change.

The intervention also drew on the Theory of Planned Behavior, which posits that the most important determinant of behavior is a person's behavioral intent, which is, in turn, influenced by knowledge, attitudes, and subjective norms (Madden et al. 1992). This intervention was designed to influence intent to use condoms by increasing HIV/AIDS-related knowledge and creating more positive attitudes and perceived norms supporting HIV/STI risk reduction among truckers (through education and VCT for HIV).

\section{Intervention Activities}

The multi-component intervention consisted of the implementation of a health unit at the customs station, providing VCT, syndromic management of STIs, and other non-sexual health-related services; individual and group education and outreach in the customs area; condom promotion and free distribution of condoms; and educational behavior change campaign and distribution of campaign materials; and a variety of brief interventions related to other aspects of health of concern to truckers, including workshops conducted by outreach workers outside the health unit on themes such as nutrition and hypertension.

\section{Health post}

The health post, referred to as the Trailer da Saúde, was opened inside the customs station in Foz do Iguaçu in September 2003. The trailer was furnished with four rooms: two for counseling; one for examination for syndromic management; and one for blood, glucose, and blood pressure testing. The trailer also included a small staff room; a restroom; and a mini kitchen/laboratory for centrofusion of blood, refrigeration, and labeling and storage of samples. The trailer was open Monday through Friday from 8 a.m. to 6 p.m., and staffed by a nurse, two part-time health educators, and four part-time VCT counselors. In addition the trailer and all project activities were supervised by a project coordinator with an office assistant.

In order to standardize research procedures, outreach, and clinical attention, and to assure high quality of care, the fieldwork team was trained on use of research instruments, HIV/STI counseling (including additional hours of practical training on HIV/STI counseling for the psychologists), syndromic approach to STI management, and theoretical/practical training on health education. Overall, the clinic staff could 
provide services to 150-160 truckers per month; the actual average number of consultations was slightly over 110 per month, during a period of 18 months.

All truckers were invited to undergo VCT services, including pre-test counseling, a blood test for HIV and syphilis, and a follow-up visit in 15 days to receive test results and post-test counseling. Counseling was client-centered, and based on the Ministry of Health's National Guidelines for Pre- and Post-test Counseling for HIV (Programa Nacional de DST/Aids, 2007). In addition, all truckers were offered a consultation and syndromic management and treatment on-site, if they had symptoms suggestive of an STI. Those diagnosed with syphilis via a blood test were referred to an STI clinic in Foz do Iguaçu for free treatment and monitoring. HIV-positive truckers were referred to a conveniently located HIV reference center for free treatment and monitoring. Non-HIV/STI-related services included blood pressure measurement and blood sugar exams for diabetes (glucose tests), and were available to all truckers, regardless of their decision to undergo VCT or not. Services were offered to both Brazilian and nonBrazilian truckers, and were available in Spanish and Portuguese.

\section{Behavior change communication (BCC) campaign}

Media

Information, education, and communication (IEC) materials were designed to target truckers in such a way as to empower them, using positive, destigmatizing images. Truckers took great pride in their trucks and in the fact that most were married men, supporting their families. As such, the campaign image included a married trucker giving a thumbs-up sign in front of a red truck with the slogan, "Truckers, Yes! And Prevention too!” The campaign materials included color pamphlets, stickers, and posters printed in both Portuguese and Spanish. Additionally, the campaign was displayed on large billboards along major trucking routes around Foz do Iguaçu, and radio spots with a campaign jingle were played for approximately two months. The media campaign, including the jingles and billboards, was implemented for a limited time only due to a loss of funding by the project partner responsible for the campaign, DKT. Though condoms were provided by DKT only for a limited time as well, the Municipal AIDS Program of Foz do Iguaçu stepped in and was able to continue to supply condoms to the project.

In the last six months of the intervention period, an interactive multimedia kiosk referred to as "Computador da Saúde” ("Health Computer") was installed next to the trailer. The health computer allowed clients to use an interactive educational program with six topic modules, including HIV and AIDS, STIs, drugs, alcohol, nutrition (including information on diabetes, cholesterol, hypertension, diet, and exercise), and general information on the Saúde na Estrada project. Within each topic area, the user had access to visual and audio health information in Portuguese or Spanish, which catered to low literacy if necessary. In addition, each module included games such as hangman and knowledge quizzes designed to improve information retention. Finally, each module contained a section on interesting facts relevant to the topic. In order to provide the user with a private and individual session, the computer was placed on a small table in a partially enclosed space. Health educators were instrumental in introducing the application to drivers, encouraging drivers to try using the kiosk and assisting interested drivers to initiate their sessions.

\section{Outreach}

The educators' principal role was to provide person-to-person and/or group-based educational messages to drivers (including informal conversations fielding doubts or concerns about HIV and STIs), to distribute educational materials, and to invite truckers to visit the trailer. The educators (outreach 


\section{Hgrizons}

workers) circulated throughout the customs area, with one member always close to the testing area for orientation and enrollment of truck drivers interested in VCT. Educational activities were usually conducted several times each day in small groups of no more than four or five truckers. Due to the unpredictable flow of drivers accessing the trailer as well as the considerable number of drivers that visited the trailer multiple times, it was important for educators to adapt their educational strategies and outreach to meet the diverse needs and numbers of people. A number of tools to facilitate dissemination of prevention messages were implemented, including pictorial visual aids and models of the male and female reproductive system (used to demonstrate condom use), as well as educational games. A video cassette player and television were also available for use in the recreation area to accompany the discussions. 


\section{I ntervention Results}

\section{Study Population Profiles at Baseline}

Key sociodemographic and occupational characteristics of the surveyed populations of truckers at the intervention site (Foz do Iguaçu) and the comparison site (Uruguaiana) are summarized below. For the two sites combined, the median age was 40 , ranging from 18-80 years; the median years of schooling was 8 , with a range of $0-22$ years. Almost three quarters of truckers interviewed were Brazilian and over 87 percent were married or living with a primary partner. Most truckers had held their jobs for many years (median 15 years, ranging from 0 to 57 years), and reported traveling frequently, spending most of their time on the road. The median months spent at home per year was only two; half of the respondents spent only 3-9 nights at home in the past four weeks. Across both sites, 48 percent of truckers averaged trips lasting 1-2 weeks at a time; 25 percent had average trip durations of 2-4 weeks. Sociodemographic characteristics between baseline and follow-up were similar within each site (data not shown).

As documented in other studies with mobile populations, a sizeable proportion of the surveyed truckers reported sexual risk behaviors at baseline. For example, 45 percent of respondents reported having concurrent sexual partners in the past six months. Reported condom use varied widely by type of partner, with truckers rarely reporting condom use with regular partners, commonly reporting consistent condom use with commercial partners, and reporting most variability in condom use with occasional partners, with whom consistent use stood at 55 percent and 67 percent in Foz do Iguaçu and Uruguaiana, respectively.

When examined by site, most characteristics, such as age and number of years working as a truck driver, were similar between the intervention and comparison site (see Table 1). The proportion of Brazilians in each site was comparable and the proportion of married or cohabiting respondents was similar.

Comparable proportions in each city reported sexual partnerships and concurrent partners. However, there were a few notable differences between the respondents at the two sites. There were more Paraguayan respondents in Foz do Iguaçu and more Argentines surveyed in Uruguaiana (reflecting the location of the towns). A larger proportion of respondents in Foz do Iguaçu than those in Uruguaiana reported low levels of formal education (i.e., four years or less) and truckers in Foz do Iguaçu reported somewhat shorter trip lengths and more nights spent at home than those in Uruguaiana. Finally, compared with respondents in Foz do Iguaçu, more respondents in Uruguaiana reported always using a condom with occasional partners during the past six months (while condom use with both commercial partners and primary partners was similar). 


\section{Hgrizons}

Table 1 Sociodemographic and occupational characteristics of participants by site at baseline (2003)

\begin{tabular}{|c|c|c|c|}
\hline & $\begin{array}{l}\text { Foz do Iguaçu } \\
(\mathrm{n}=779)^{\dagger}\end{array}$ & $\begin{array}{l}\text { Uruguaiana } \\
(\mathrm{n}=996)^{\dagger}\end{array}$ & p-value \\
\hline \multicolumn{4}{|l|}{ Sociodemographic } \\
\hline Age: median (IQR) ${ }^{\ddagger}$ & $41(32-48)$ & $40(32-47)$ & 0.02 \\
\hline \multicolumn{4}{|l|}{ Relationship Status: $\mathrm{n}(\%)$} \\
\hline Married/cohabiting & $684(88)$ & $861(87)$ & \multirow{3}{*}{0.68} \\
\hline Girlfriend but not living together & $59(8)$ & $83(8)$ & \\
\hline Single & $35(4)$ & $51(5)$ & \\
\hline \multicolumn{4}{|l|}{ Nationality: n (\%) } \\
\hline Brazilian & $526(68)$ & $771(77)$ & \multirow{5}{*}{$<0.01$} \\
\hline Paraguayan & $174(22)$ & $1(0.1)$ & \\
\hline Argentine & $61(8)$ & $166(17)$ & \\
\hline Chilean & $18(2)$ & $45(5)$ & \\
\hline Other & $0(0)$ & $13(1)$ & \\
\hline Education: median (IQR) & $7(5-10)$ & $8(6-10)$ & $<0.01$ \\
\hline Years working as truck driver: median (IQR) & $15(7-23)$ & $15(8-24)$ & 0.48 \\
\hline Income: median (IQR) & $354(246-527)$ & $456(351-531)$ & $<0.01$ \\
\hline \multicolumn{4}{|l|}{ Mobility } \\
\hline Nights at home last month: median (IQR) & $6(3-10)$ & $4(2-8)$ & $<0.01$ \\
\hline \multicolumn{4}{|l|}{ Average length of trips: $n(\%)$} \\
\hline Less than 1 week & $223(29)$ & $113(11)$ & \multirow{5}{*}{$<0.01$} \\
\hline $1-2$ weeks & $374(48)$ & $482(48)$ & \\
\hline 2-4 weeks & 137 (18) & $305(31)$ & \\
\hline 4 weeks or more & $37(5)$ & $58(6)$ & \\
\hline Variable length & $7(0.9)$ & $37(4)$ & \\
\hline \multicolumn{4}{|l|}{ Sexual partnerships } \\
\hline \multicolumn{4}{|l|}{ Sexual relations in past 6 months: $\mathrm{n}(\%)$} \\
\hline Had sex with principal partner & 736 (99) & $932(99)$ & 0.53 \\
\hline Had sex with occasional partner(s) & $195(25)$ & $236(24)$ & 0.95 \\
\hline Had sex with commercial partner(s) & $248(32)$ & $321(32)$ & 0.51 \\
\hline $\begin{array}{l}\text { Had concurrent sexual partners in past } 6 \text { months: } \\
\mathrm{n}(\%)\end{array}$ & $358(46)$ & $450(45)$ & 0.77 \\
\hline \multicolumn{4}{|l|}{ Condom use* } \\
\hline \multicolumn{4}{|l|}{$\begin{array}{l}\text { Used condom with primary partner over past } 6 \\
\text { months: } \mathbf{n}(\%)\end{array}$} \\
\hline Always & $68(9)$ & $85(9)$ & \multirow[t]{3}{*}{0.40} \\
\hline Sometimes & $133(18)$ & $192(21)$ & \\
\hline Never & $535(73)$ & $651(70)$ & \\
\hline \multicolumn{4}{|l|}{$\begin{array}{l}\text { Used condom with occasional partner over } \\
\text { past } 6 \text { months: } \mathrm{n}(\%)\end{array}$} \\
\hline Always & $77(56)$ & $121(67)$ & \multirow[t]{3}{*}{0.02} \\
\hline Sometimes & $16(12)$ & $25(14)$ & \\
\hline Never & 45 (33) & 35 (19) & \\
\hline \multicolumn{4}{|l|}{$\begin{array}{l}\text { Used condom with commercial sex partner } \\
\text { over past } 6 \text { months: } n(\%)\end{array}$} \\
\hline Always & $68(81)$ & $106(88)$ & \multirow[t]{3}{*}{0.28} \\
\hline Sometimes & $12(14)$ & $9(7)$ & \\
\hline Never & $4(5)$ & $6(5)$ & \\
\hline
\end{tabular}

${ }^{\dagger}$ Numbers vary slightly due to missing data

${ }^{\ddagger} \mathrm{QQR}=$ inter-quartile range

* Among sub-groups of respondents with each type of partner in the past 6 months who reported having vaginal sex more than once. 


\section{Exposure to the Intervention and Service Statistics}

The intervention successfully exposed a substantial proportion of truckers to specific activities. Just over half of the systematic sample of truckers who gave follow-up interviews at the intervention site, Foz do Iguaçu, had participated in the intervention (see Table 2). A third (32 percent) reported visiting the trailer and participating in VCT, and an additional quarter (22 percent) declared that they did not receive VCT but did participate in the educational activities or received some kind of educational materials or condoms from outreach educators or counselors. Only 13 percent had not heard of the project in the intervention site.

It also became clear that a small proportion of truckers (13 percent) interviewed in the comparison site, Uruguaiana, had traveled through Foz do Iguaçu and either accessed VCT at the trailer-based health post in Foz do Iguaçu or had participated in educational activities and/or received educational materials in the intervention site (see Table 2).

Table 2 Reported exposure to intervention activities during the evaluation phase at Foz do Iguaçu (intervention site) and Uruguaiana (comparison site)

\begin{tabular}{lcc}
\hline Exposure to intervention activities at Foz do Iguaçu & $\begin{array}{c}\text { Foz do Iguaçu } \\
\text { (n= 1,204) } \\
\mathbf{n}(\mathbf{\%})\end{array}$ & $\begin{array}{c}\text { Uruguaiana } \\
\text { (n= 1,211) } \\
\mathbf{n ~ ( \% )}\end{array}$ \\
\hline Utilized VCT services at the trailer in Foz * & $381(32)$ & $52(4)$ \\
Utilized educational activities only** & $258(22)$ & $104(9)$ \\
Only heard about the intervention & $396(33)$ & $263(22)$ \\
Did not know about the intervention & $159(13)$ & $755(64)$ \\
\hline
\end{tabular}

* Most (80\%) of these individuals also participated in educational activities.

** Educational activities included talking to a health educator, participating in an educational activity, watching an educational video at the trailer, using the kiosk, and receiving educational materials and/or condoms.

Service statistics collected during the 18 months of the intervention also indicated that the project activities reached thousands of truckers with educational activities, materials, and condoms (see Table 3).

Table 3 Process indicators at intervention end

\begin{tabular}{lc}
\hline Intervention components & Number \\
\hline Truckers using VCT services & 1,945 \\
Truckers participating in HIVIAIDS prevention talks & 2,524 \\
Truckers participating in other educational activities & 5,489 \\
Educational booklets and pamphlets distributed & 9,831 \\
Condoms distributed & 35,613 \\
\hline
\end{tabular}

The health computer was used by a relatively small number of truckers; an average of 35 users per month accessed the system following its introduction in September 2004, one year into the intervention. Despite technical and maintenance problems that emerged during the computer use, a qualitative evaluation showed that it was well accepted among those truckers who had previous experience with computer use; 


\section{Hgrizons}

low utilization was found to be due to a lack of computer experience/knowledge and embarrassment to try it or to ask for help.

\section{Physical and Psychosocial Mobility}

Though mobility is often defined only as the process of physical movement, it is experienced not only physically but also psychosocially. Truckers were asked questions regarding their physical mobility (time spent away from home) and psychosocial mobility (feelings about being on the road) (see Table 4). The association of sexual behavior with physical and psychosocial mobility was examined using logistic and negative binomial regression.

Table 4 Statements on physical mobility

\begin{tabular}{lc}
\hline Statement & Percent agreeing \\
\hline Being a truck driver means I have more freedom to do what I'd like & 33 \\
Being on the road often makes me feel lonely & 83 \\
When I am on the road I can do things that I don't do at home & 34 \\
When I am on the road I don't have anyone telling me what to do & 54 \\
I think it's easier to have sexual relationships on the road because they are not & 33 \\
\hline permanent & \\
\hline
\end{tabular}

\section{Physical mobility}

Only half of the truckers reported spending more than five nights in their homes in the four weeks preceding the baseline interview. Truckers who spent more time at home were less likely to report having commercial partners in the prior six months $(\mathrm{p}<.05)$ and had reduced odds of having a concurrent partner in the past month $(\mathrm{p}<.05)$. Similarly, men whose routes were $1-2$ weeks, $2-4$ weeks, or more than 4 weeks long were significantly more likely to report having commercial sex partners (adjusted OR $=1.5$, 1.8, and 2.3, respectively) than men with trips of less than one week duration. Spending time away from home was not only associated with having sexual partners, but also with having more commercial and concurrent partners (data not shown).

\section{Psychosocial mobility}

Using cluster analysis, truckers were grouped into categories based on their reported perceptions of the liminal environment, or traveling outside of one's normal social environment. The clustering procedure yielded three dispositions towards the liminal environment: group one $(n=557)$ gave responses indicating a sense of freedom on the road and more permissive attitudes while traveling; group two ( $\mathrm{n}=$ 740) gave responses indicating that while risky behaviors were facilitated by being on the road, they still did not feel free to act differently; group three $(n=474)$ perceived the travel environment as similar to the home environment, and reported behaving accordingly.

As in the case of physical mobility, truckers' attitudes about travel were also correlated with sexual risk behaviors. Logistic regression demonstrated that the truckers who saw the travel environment as most 
permissive were significantly more likely to have sexual partners (see Figure 1). For more detail about this analysis and the relationship between mobility and sexual risk, see Lippman et al (under review).

Figure 1 Report of sexual partnerships by liminal cluster category

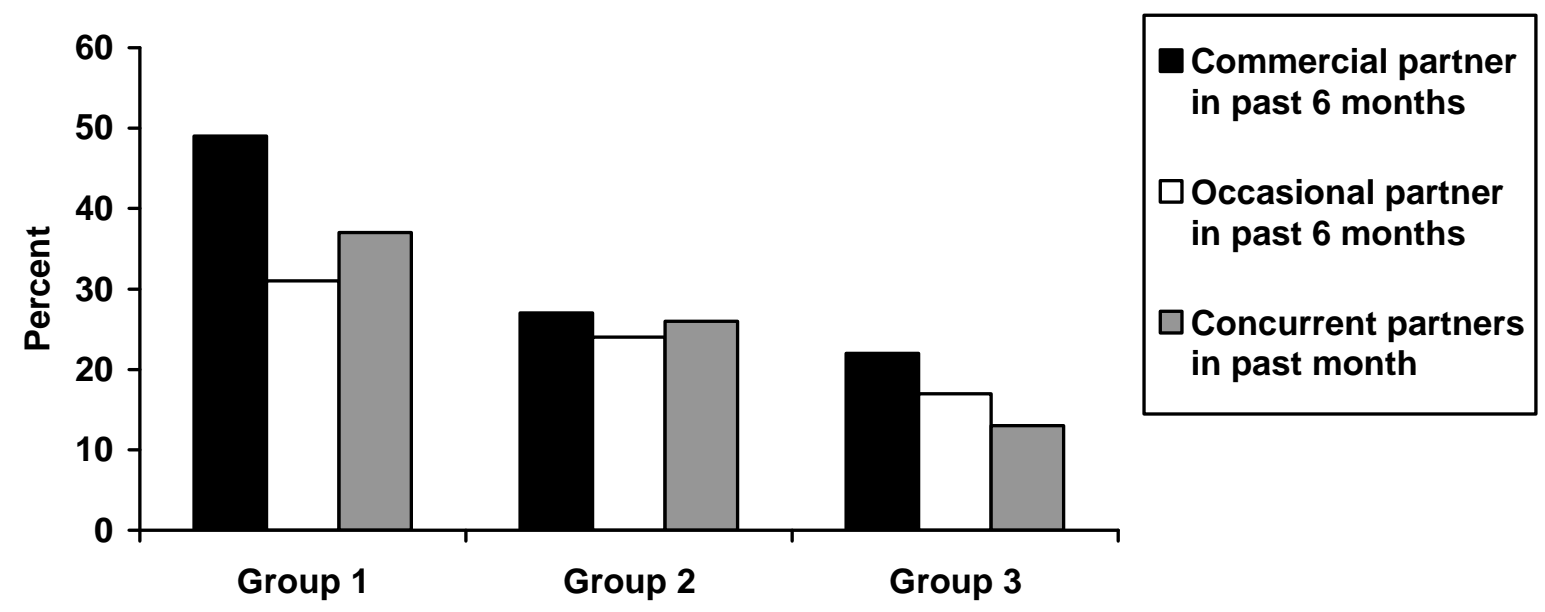

\section{HI V-related Stigma}

Fifteen questions were included in the survey on HIV-related stigma, based on a literature review, researcher experience in other contexts, and formative research in Brazil. Associations between stigma items and variables measuring service utilization were examined at baseline using Pearson's chi-square tests.

Truckers reported both fear of stigma and stigmatizing attitudes. For example, almost half (44 percent) agreed with the statement "If I had AIDS, I would be fired from my work," 60 percent agreed with the statement "AIDS is a punishment for bad behavior," and only 34 percent agreed with the statement "I would feel comfortable traveling with someone with HIV/AIDS in my truck." Twelve of the 15 stigma items were significantly correlated $(\mathrm{p}<.05)$ with ever having been tested for HIV, and six were correlated with knowing where to obtain a free test. Those who demonstrated stigmatizing attitudes or feared discrimination were less likely to have ever been tested for HIV and less likely to know where to get a free HIV test.

For more detailed information on HIV-related stigma from the perspective of truckers, as well as the relationship between stigma, service utilization, and HIV status disclosure, see Pulerwitz et al. (under review).

\section{HIV Testing: Quality of VCT and Change in Utilization Over Time}

At baseline, less than half of respondents had ever had an HIV test. Furthermore, at baseline, respondents in the comparison site were more likely than those in the intervention site to have ever had an HIV test (see Table 5). By follow-up, the opposite was true: ever having an HIV test increased by 49 percent in the intervention site and by only 15 percent in the comparison site, making truckers in the intervention site 


\section{Hgrizons}

more likely to have ever received an HIV test. An additional 105 men and women who worked at the customs station where the trailer was located also utilized VCT.

Table 5 HIV testing utilization history by site at baseline (2003) and follow-up (2005)

\begin{tabular}{|c|c|c|c|c|c|c|}
\hline \multirow{2}{*}{$\begin{array}{l}\text { Survey items on } \\
\text { HIV testing utilization }\end{array}$} & \multicolumn{3}{|c|}{ Uruguaiana } & \multicolumn{3}{|c|}{ Foz do Iguaçu } \\
\hline & $\begin{array}{l}\text { Baseline } \\
(\mathrm{n}=996)\end{array}$ & $\begin{array}{l}\text { Follow-up } \\
(\mathrm{n}=1,211)\end{array}$ & $\begin{array}{c}\% \\
\text { change }\end{array}$ & $\begin{array}{l}\text { Baseline } \\
(\mathrm{n}=779) \\
\end{array}$ & $\begin{array}{l}\text { Follow-up } \\
(\mathrm{n}=1,204)\end{array}$ & $\begin{array}{c}\% \\
\text { change }\end{array}$ \\
\hline $\begin{array}{l}\text { Has ever been tested for } \\
\text { HIV: } n(\%)^{\dagger}\end{array}$ & $449(46)$ & $625(53)$ & $15.2 \%$ & $300(39)$ & $686(58)$ & $48.7 \%$ \\
\hline $\begin{array}{l}\text { Knows where to get a free } \\
\text { HIV test, among those not } \\
\text { previously tested: } n(\%)\end{array}$ & $219(41)$ & $244(44)$ & $7.3 \%$ & $151(32)$ & 255 (51) & $59.4 \%$ \\
\hline
\end{tabular}

Note: All percent changes are significant $(p<.01)$ within city and between cities from baseline to follow up.

$\dagger$ Numbers vary slightly from total sample due to missing data.

The intervention was highly successful at encouraging the mobile truckers to return for test results. At the intervention health post, 1,821 truckers gave a blood sample for HIV testing, and of these, 82 percent returned to receive test results and post-test counseling. Considering the mobile nature of the population tested, the return rate was quite high and rivaled return rates documented at high quality testing services serving more stable populations throughout Brazil. For example, the municipal reference clinic in Foz do Iguaçu reported a monthly average of 85 percent return over three years.

The intervention was also successful in providing pre- and post-test counseling in addition to testing; there was a significant increase in truckers surveyed who reported receiving counseling (see Table 6). While pre- and post-test counseling is officially required in Brazil, often neither is provided, or it may consist only of a group educational discussion and not focus on individual clients. In fact, baseline data indicated that only 52 percent of truckers who had been tested for HIV reported that they had received pre-test counseling, and 34 percent reported receiving post-test counseling, including truckers not returning for test results (approximately 6 percent of those tested). During follow-up, among truckers at the intervention site who had been tested, 77 and 68 percent reported having received pre- and post-test counseling, respectively, compared to only 55 and 36 percent of truckers at the comparison site (approximately 4 percent at both sites did not receive test results). Examining only those truckers who reported having participated in VCT activities at the intervention health post, 97 percent and 93 percent confirmed having gone through pre- and post-test counseling, respectively (data not shown). 
Table 6 Pre- and post-test counseling received among truckers who underwent HIV testing at baseline (2003) and follow-up (2005)

\begin{tabular}{lccc|ccc}
\hline $\begin{array}{l}\text { Survey items on } \\
\text { counseling }\end{array}$ & $\begin{array}{c}\text { Baseline } \\
(\mathbf{n = 9 9 6 )}\end{array}$ & $\begin{array}{c}\text { Uruguaiana } \\
\text { Follow-up } \\
(\mathbf{n = 1 , 2 1 1 )}\end{array}$ & $\begin{array}{c}\text { \% } \\
\text { change }\end{array}$ & $\begin{array}{c}\text { Foz do Iguaçu } \\
\text { Baseline } \\
\text { (n= 779) }\end{array}$ & $\begin{array}{c}\text { Follow-up } \\
\text { (n= 1,204) }\end{array}$ & $\begin{array}{c}\text { \% } \\
\text { change }\end{array}$ \\
\hline Truckers tested: $\mathrm{n}$ & 449 & 625 & & 300 & 686 & \\
$\begin{array}{l}\text { Reported pre-test } \\
\text { counseling: } \mathrm{n}(\%)\end{array}$ & $227(51)$ & $341(55)$ & $7.8 \%$ & $156(53)$ & $521(77)$ & $45.3 \%$ \\
$\begin{array}{l}\text { Reported post-test } \\
\text { counseling: } \mathrm{n}(\%)^{*}\end{array}$ & $157(35)$ & $227(36)$ & $2.9 \%$ & $94(32)$ & $459(68)$ & $112.5 \%$ \\
\hline
\end{tabular}

Note: Percent change significant $(p<.01)$ within Foz do Iguaçu and between cities from baseline to follow-up.

* Includes truckers not returning for test results.

While a fair number of truckers did not access the health post, based on survey results, truckers who did utilize VCT services were comparable to those who did not in terms of sociodemographic characteristics, with the exception that the intervention attracted more Paraguayans. This is likely due to the fact that access to health services is limited in Paraguay.

\section{Partner Communication about Condom Use and Testing}

A principal focus of both the educational outreach and the counseling services at the trailer-based health post was to improve communication around issues of condom use, HIV testing, and STIs. It was hypothesized that little sexual behavior change would occur without encouraging truckers to communicate with all sexual partners. Communication with all partners (regular, commercial, and occasional) improved in the intervention site but not in the comparison site (see Table 7).

Specifically, there was a significant increase in communication about condoms with all partners (occasional, commercial, and regular) in Foz do Iguaçu following the intervention. However, communication about condom use did not significantly change in Uruguaiana in the two years between surveys with any partner type. Similarly, more truckers in the intervention site reported discussing HIV testing with their partners, with the greatest percent change demonstrated in truckers who spoke to their regular partners about testing. Communication around STIs improved significantly only with regular partners. 


\section{Hgrizons}

Table 7 Communication about condom use, HIV testing, and STIs with last sexual partners by site at baseline (2003) and follow-up (2005)

\begin{tabular}{|c|c|c|c|c|c|c|}
\hline \multirow{2}{*}{$\begin{array}{l}\text { Survey items on } \\
\text { key points of communication }\end{array}$} & \multicolumn{3}{|c|}{ Uruguaiana } & \multicolumn{3}{|c|}{ Foz do Iguaçu } \\
\hline & $\begin{array}{l}\text { Baseline } \\
(n=996)\end{array}$ & $\begin{array}{l}\text { Follow-up } \\
(n=1,211)\end{array}$ & $\begin{array}{c}\% \\
\text { change }\end{array}$ & $\begin{array}{l}\text { Baseline } \\
(\mathrm{n}=779)\end{array}$ & $\begin{array}{l}\text { Follow-up } \\
(n=1,204)\end{array}$ & $\begin{array}{c}\% \\
\text { change }\end{array}$ \\
\hline Occasional pa & $n=237$ & $n=272$ & & $n=195$ & $n=240$ & \\
\hline Talked about using condoms & $200(84)$ & $229(84)$ & $-0.2 \%$ & $149(76)$ & $207(87)$ & $13.4 \%^{\dagger \ddagger}$ \\
\hline Talked about getting HIV test & $87(37)$ & $95(35)$ & $-6.2 \%$ & $54(28)$ & $82(34)$ & $22.5 \%{ }^{\dagger \mp}$ \\
\hline Asked if partner had an STI & $109(47)$ & $119(44)$ & $-6.0 \%$ & $88(46)$ & $119(50)$ & $8.8 \%$ \\
\hline Commercial partner & $n=319$ & $n=363$ & & $n=248$ & $n=355$ & \\
\hline Talked about using condoms & $282(89)$ & $317(88)$ & $-1.0 \%$ & $206(84)$ & $316(89)$ & $6.7 \%^{\dagger}$ \\
\hline Talked about getting HIV test & 60 (19) & $58(16)$ & $-14.3 \%$ & $40(16)$ & $79(22)$ & $38.3 \%^{\ddagger}$ \\
\hline Asked if partner had an STI & $116(37)$ & $111(31)$ & $-15.6 \%$ & $95(38)$ & $113(32)$ & $-17.4 \%$ \\
\hline Regular partner & $n=945$ & $n=1,134$ & & $n=743$ & $n=1,147$ & \\
\hline Talked about using condoms & $736(79)$ & $921(82)$ & $3.7 \%$ & $555(76)$ & $951(84)$ & $10.6 \%^{\dagger+}$ \\
\hline Talk & 517 & 617 & $-1.3 \%$ & 302 & 720 & $54.3 \%^{\dagger+}$ \\
\hline Asked if partner had an STI & $430(46)$ & $578(51)$ & $11.0 \%^{\dagger}$ & $346(47)$ & $663(59)$ & $23.9 \%^{\dagger}$ \\
\hline
\end{tabular}

${ }^{\dagger}$ Percent change from baseline to follow up significant within city $(p<.05)$

₹ Percent change from baseline to follow up significant between cities $(p<.05)$

\section{Sexual Risk Behaviors}

Although the intervention sought to promote safer sexual behaviors with all partners, condom use with commercial partners was extremely common before the intervention began and truckers showed considerable resistance to using condoms with regular or fixed partners. Even so, condom use with commercial partners increased in the comparison city while the same was not true in the intervention city. Condom use with regular partners improved, albeit non-significantly, in both cities. In the comparison community, fewer truckers reported unprotected sex with their regular partner at follow-up and more reported always using condoms, although the proportion was still low (12 percent). In Foz do Iguaçu; there was a trend towards more truckers reporting ever using a condom with their regular partners (see Table 8).

Evidence of intervention impact was found with the sexual risk behavior that was hypothetically most amenable to behavior change: condom use with occasional partners. Participants who reported ever using condoms with an occasional partner increased by 21 percent in the intervention site while decreasing 2.5 percent in the comparison site at follow-up compared with baseline (see Table 8). In fact, baseline rates in the comparison site were higher than in the control site, and by follow up the opposite was true. Most of this reported change in condom use with occasional partners occurred among truckers who never or rarely used condoms at baseline: the proportion of truckers in the intervention site reporting never or rarely using condoms with occasional partners decreased while the proportion reporting always using condoms 
increased. Corresponding data from the comparison site showed little or no change in frequency of condom use with occasional partners.

Table 8 Key sexual risk behaviors in last six months by site at baseline (2003) and follow-up (2005)

\begin{tabular}{|c|c|c|c|c|c|c|}
\hline \multirow{2}{*}{$\begin{array}{l}\text { Survey items on key sexual risk } \\
\text { behaviors }\end{array}$} & \multicolumn{3}{|c|}{ Uruguaiana } & \multicolumn{3}{|c|}{ Foz do Iguaçu } \\
\hline & $\begin{array}{l}\text { Baseline } \\
(n=996)\end{array}$ & $\begin{array}{l}\text { Follow-up } \\
(n=1,211)\end{array}$ & $\begin{array}{c}\% \\
\text { change }\end{array}$ & $\begin{array}{l}\text { Baseline } \\
(n=779)\end{array}$ & $\begin{array}{l}\text { Follow-up } \\
(n=1,204)\end{array}$ & $\begin{array}{c}\% \\
\text { change }\end{array}$ \\
\hline Occasional partner & $\mathrm{n}=237$ & $n=272$ & & $n=195$ & $\mathrm{n}=240$ & \\
\hline Always used condom: $\mathrm{n}(\%)^{\star}$ & $121(67)$ & $140(69)$ & $3.0 \%$ & $76(55)$ & $112(62)$ & $12.7 \%$ \\
\hline Ever used condom: $\mathrm{n}(\%)^{\star}$ & $146(81)$ & $159(79)$ & $-2.5 \%$ & $92(67)$ & $146(81)$ & $20.9 \%{ }^{\dagger \ddagger}$ \\
\hline Commercial partner & $\mathrm{n}=319$ & $n=363$ & & $n=248$ & $n=355$ & \\
\hline Always used condom: $\mathrm{n}(\%)^{*}$ & $106(88)$ & $140(95)$ & $8.0 \%^{\dagger}$ & $68(79)$ & $132(84)$ & $6.3 \%$ \\
\hline Ever used condom: $\mathrm{n}(\%)^{\star}$ & $115(95)$ & $146(99)$ & $4.2 \%$ & $80(93)$ & $142(90)$ & $-3.2 \%$ \\
\hline Regular partner & $n=945$ & $n=1,134$ & & $n=743$ & $n=1,147$ & \\
\hline Always used condom: $\mathrm{n}(\%)^{\star}$ & $85(9)$ & $130(12)$ & $20.9 \%$ & $68(9)$ & $105(9)$ & $0.0 \%$ \\
\hline Ever used condom: $\mathrm{n}(\%)^{*}$ & $277(30)$ & $357(32)$ & $6.7 \%$ & $201(27)$ & $347(31)$ & $14.8 \%$ \\
\hline \multicolumn{7}{|l|}{ Among all partner types } \\
\hline $\begin{array}{l}\text { Had concurrent sexual partners } \\
\text { in past } 6 \text { months: } \mathrm{n}(\%)\end{array}$ & $450(45)$ & $506(42)$ & $-6.7 \%$ & $357(46)$ & $487(41)$ & $-12.2 \%^{\dagger}$ \\
\hline
\end{tabular}

* Among sub-groups of respondents who reported having more than 1 sexual contact with partner type in the past 6 months.

$\dagger$ Percent change from baseline to follow-up significant within city $(p<.05)$.

‡ Percent change significant from baseline to follow-up between cities $(p<.05)$.

A significant reduction in the number of concurrent sexual partners was also found in the intervention site, but not in the comparison site. At baseline, almost half of the truckers reported a primary sexual partner and a secondary sexual partner during the six months prior to the survey. At follow up, two years after the baseline, fewer truckers reported concurrent sexual partners, with a significant reduction (12 percent) found only in the intervention site.

Qualitative data provide some additional insights into the changes in sexual risk behavior. According to both Brazilian and Spanish speaking truckers who participated in the intervention, the activities led to raised awareness of risk and improved truckers' knowledge on HIV/STI prevention.

Since I went there [to the health post], I got it in my mind that I had to take care of myself

FGD, Paraguayan trucker

We became [...] more alert about transmissible diseases, those things, so... we do not get

"involved" with any women anymore....

FGD, Brazilian trucker 


\section{Hgrizons}

\section{HIV/ STI Symptoms, Prevalence, and Treatment}

A total of 1,821 truckers had a blood sample taken for HIV testing, and 1,825 for syphilis testing. Only five of the truckers tested positive for HIV ( 0.3 percent; see Table 9$)$, three of whom were referred to the municipal HIV/STI program for follow-up. One did not consent to come back to be referred, and the fifth could not be reached. Syphilis prevalence (active and past infection) was 4.4 percent. This rate was substantially lower than that found among long distance truckers in the Brazilian port of Santos (13 percent) (Lacerda et al. 1997). Thirty-four of the 81 individuals who tested positive for syphilis (42 percent) were attended by the project nurse who referred them to a local STI clinic for free treatment. The rest of the truckers who tested positive for syphilis were either counseled by the nurse in the project but chose not to be treated at the STI clinic in Foz do Iguaçu, preferring to seek treatment and follow-up services in their home cities or countries, or did not return for their test result. Test results from the subset of truckers $(\mathrm{n}=799)$ participating in the nested study for hepatitis B and herpes simplex virus $2(\mathrm{HSV}-2)$ can also be found in Table 9 .

Table 9 Prevalence of HIV, syphilis, HSV-2 and hepatitis B among truck drivers in the triple border (Brazil, Paraguay, and Argentina), 2003-2005

\begin{tabular}{lc}
\hline STI & $\%(95 \% \mathrm{CI})$ \\
\hline HIV (5/1821) & $0.3(0.09-0.6)$ \\
Syphilis (81/1829) & $4.4(3.5-5.5)$ \\
Hepatitis B & \\
$\quad$ Active (18/799) & $2.4(1.1-3.5)$ \\
$\quad$ Immune (239/799) & $29.8(26.6-33.1)$ \\
HSV-2 (222/799) $^{\dagger}$ & $26.6(23.5-29.7)$ \\
\hline
\end{tabular}

${ }^{\dagger}$ Prevalence estimates weighted to reflect sampling design

Truckers who reported current STI symptoms while visiting the health post were offered treatment (with a syndromic management approach). Of the truckers who received pre-test HIV counseling $(\mathrm{n}=1,945), 18$ percent reported having one or more STI symptoms in the previous six months. Of those, 42 percent declared having the symptoms at the time of the interview and 50 percent of them agreed to an appointment with the nurse at that visit. In addition, the nurse saw 83 truckers who spontaneously presented at the health post for genital or other possible STI-related complaints. In total, there were 158 truckers assessed for STI symptoms, and 31 truckers visited the health post for STI symptoms more than once. Based on the syndromic diagnoses, 28 percent had a genital ulcer, 22 percent had urethral discharge, 15 percent had warts, and 3 percent had a suspected (unconfirmed) STI diagnosis (including condyloma latum or secondary syphilis warts, genital ulcer, and lymphogranuloma venereum). In addition, 19 percent were diagnosed with other general health problems, and received counseling or were referred to a clinical service. 


\section{Truckers' Perception of the I ntervention: Non-stigmatizing, Accessible, and Useful}

The holistic strategy of offering blood pressure measurement and glucose testing together with VCT for HIV and syphilis was well accepted by truckers. In fact, a number of drivers only accessed the trailer initially for glucose testing and to measure their blood pressure. This alternative entry into trailer services was beneficial, as many of the truckers seeking non-HIV related services ended up participating in HIV/STI educational discussions. For example, when health educators began group discussions or activities, a number of the drivers seeking only blood pressure and glucose measures stayed to listen and learn about HIV/AIDS.

They teach you that AIDS can be transmitted, that it is dangerous, that it can kill you, but also that there are ways of treating it. The education is really very good.

FGD, Paraguayan user

Armed with more information, truckers grew increasingly more comfortable with the topic of HIV/STIs and engaged the educators, asking questions and making comments, and often deciding to participate in the VCT services. Many VCT users continued going to the trailer each time they passed through the customs station to talk with the educators about health issues/concerns or just for a friendly conversation. Educators took advantage of these visits by inviting drivers to participate in educational games or prevention-related activities.

I went there three times to take the blood pressure exam, apart from the main (VCT) exam that I did the first time I was invited. After that, from time to time I go back there to get condoms....

FGD, Brazilian user

Truckers were highly receptive to the intervention, based on both qualitative interviews and survey responses. Focus groups revealed that truckers appreciated the easy access to the trailer, as it was placed within the customs station, as well as the existence of a service focused on the truckers' welfare and health. They also strongly recommended the services to their peers because services were informative, the staff was attentive and non-judgmental, and condoms and other medications were available free of charge.

This service was the best thing in this region. Now, you have a problem and you have all you want here, not needing to go to other places-and you use the time when you are waiting for your cargo authorization papers.

FGD, Brazilian user

They never leave you without an answer or without giving you a yes or no, they always talk to us; you go there and ask for something...you always leave [the health post] satisfied.

FGD, Brazilian user

I really loved the way I was treated...the nurses and all the health workers are very helpful and kind...they know how to treat people.

FGD, Paraguayan user

Non-Brazilian service users, mainly Paraguayans, stressed the idea that free services were very important to them. In their opinion, the health post provided an experience that should be expanded and replicated in 


\section{Hgrizons}

other areas, mainly at the other side of the border, because in Paraguay there are no free services available.

...In Paraguay there isn't such a thing... So, here, on the contrary, we had it all; you can get tested for everything and everything is free of charge....

FGD, Paraguayan user

But I think that it [the trailer] should, once in awhile—at least every 2 or 3 months—go and set up for a week on the other side and try to provide services over on that [Paraguayan] side of the border....

FGD, Paraguayan user

Based on survey responses, almost all truckers who participated in the services rated the services as "great" or "good" (68 and 31 percent, respectively). The main reasons offered for the high level of satisfaction were the existence of a service that offers education, counseling, and treatment for HIV/STIs and other health conditions ( 77 percent); the easy access to services (29 percent); that they were free (12 percent); the quality of attention and of the staff ( 9 percent); and because it focused specifically on truckers (9 percent) $)^{1}$.

Among the few negative aspects truckers mentioned was shame and discomfort talking about sexual issues with female counselors and educators.

...we are embarrassed with the girls there. The girls, you arrive there, and they start to do their job, ask questions, so there are some truckers who feel embarrassed to answer, you see. For example, they ask: "Have you had anal sex, oral sex?" this kind of stuff; so there are guys who feel embarrassed to answer "if you had partners...that you paid for?" So there are people who feel ashamed you know, and embarrassed to go there."

FGD, Brazilian user

In addition to the general satisfaction with services, the majority of surveyed truckers felt that using the services was not stigmatizing: only 5 percent of the survey respondents who had participated in or heard about the intervention $(n=849)$ thought that their participation in intervention activities would cause their colleagues to believe that they might have HIV or another STI.

Despite broad approval of the intervention and the small proportion of surveyed truckers who reported worries about participation in the intervention leading to stigma from their colleagues, some truck drivers were concerned about increased stigma. Specifically, Brazilian truck drivers participating in the postintervention focus groups, but who did not participate in the intervention, expressed concern that the intervention campaign advertisements and slogan ("Caminhoneiro sim, prevenido também”-_"Trucker, yes! and Prevention too”) reinforced societal stigma against truckers as carriers of HIV and STI.

Focusing only on truckers! This makes it seem as though truckers are bringing AIDS to Argentina, to Chile, to Uruguay; this is how I see it.

FGD, Brazilian non-user

\footnotetext{
${ }^{1}$ Multiple answers permitted.
} 
This kind of disease as I see it, I imagine that this trailer there gives the impression that the driver is the one with the STD disease in this case [...] and that is not necessarily so.

FGD, Brazilian non-user

This concern over negative stereotypes of truck drivers is consistent with the findings from formative research. On the other hand, non-Brazilian non-service users tended to emphasize the importance of the health post for those who have doubts and were genuinely concerned about their health. Additionally, almost all of the truckers interviewed who accessed services did not find the intervention stigmatizing.

Though most truckers were very happy to receive the services, some echoed that their major health concerns were not related to sexual health or AIDS, but rather to nutrition, lack of exercise, and heart disease. Truckers unanimously voiced a desire for easy access to health services in general, including access to general practitioners and dentists.

It should have more things, shouldn't it? [The services] It should be broader [...] since it is related to illnesses in truck drivers, not only venereal diseases, but to diseases in general, [it should have things] such as, a dentist, an ophthalmologist....

FGD, Brazilian user

\section{Experience Working in the Customs Station}

Both truckers and project staff agreed that the customs station was the best place to set up the trailer and to implement the project, because there, the truckers had the time to participate and few other leisure activities available. Nevertheless, the implementation itself was not an easy process, mostly due to logistical difficulties resulting from a new administrative system at the customs area and the need for approval prior to project implementation from the Federal Revenue Service, which governs the customs stations.

An additional challenge inherent to working at the customs station was the time allotted to each trucker for clearance of cargo and documents. Because the Revenue Service has attempted to streamline clearance procedures, truckers had limited time within which they had to leave once their cargo had been cleared. As such, truckers were often forced to interrupt their participation in the intervention at short notice in order to avoid fines.

On the other hand, since the beginning of the project, the Director of EADI Sul was strongly supportive of the intervention and played a key role in negotiating the relevant approval processes with federal authorities. Moreover, EADI Sul was a strong and active partner for the project, covering costs of trailer maintenance such as electricity, water, and cleaning; providing a room for study coordination; and even adapting and remodeling part of the customs area to accommodate the trailer. Also, the customs station is a closed and protected area, which allowed the intervention team to work under safe conditions.

\section{Additional Benefits of the Project}

In addition to the intervention's intended effects, the project had several unexpected benefits. First, the project's implementation raised awareness of HIV/STIs as a local problem. The increased visibility of HIV/STIs helped direct the attention of city authorities toward a chronic local health hazard: prior to the intervention, an abandoned area in front of the customs station, lacking even basic sanitary conditions, 


\section{Hgrizons}

had been taken over by illegal street vendors selling alcohol, tobacco, and possibly illicit drugs. Also, commercial sex workers used the area as a venue for soliciting customers. Formative research showed that truckers had easy access to alcohol, drugs, and transactional sex, but relatively little access to condoms, posing a direct risk of HIV and STI transmission. Several months after the program's initiation, the local authorities closed down the area, citing its risks to the public's health.

Referring to the informal sex worker sector that used to thrive in the area, a trucker stated:

It [the sex worker sector and all the shacks] was removed! They removed everything and, in some sense, it was really good.... It is possible that after the trailer was installed truckers began to refrain from some behaviors and now sex workers do not come to that area anymore....

FGD, Brazilian user

In addition, EADI Sul implemented changes in their system, simplifying the procedures to liberate documents and cargo at the customs station in order to help make truckers' lives easier and more pleasant during their stay in the customs area, based on the problems described by truckers during formative research.

Finally, the project also increased the visibility of truckers' difficulties accessing high quality health services. Growing awareness helped stimulate public and private institutions to search for solutions. Despite providing strong verbal support for the project and the need to provide truckers with quality health care options, the Municipal and State Secretary of Health was not able to provide funding to continue the project after the intervention's completion. However, project implementers were able to negotiate with a private, local university, which agreed to establish a health post offering preventive activities in the areas of ophthalmology, nutrition, and physiotherapy, and to maintain the free HIV VCT services. This health post was scheduled to begin delivering services in 2007, after administrative and logistical issues were resolved. 


\section{Costs}

\section{Start-up}

The cost of the start-up of the VCT center was almost \$30,000. Expenses in preparatory meetings represent 42 percent of the total costs of the implementation phase, which is vitally important for developing interventions, particularly for gaining buy-in prior to the implementation of interventions with partners. Training the service providers required 38 percent $(\$ 11,156)$ of the start-up phase resources. The bulk of these resources consisted of trainers' and trainees' time during two training sessions comprising 10 days in total. A further 16 percent of resources $(\$ 4,841)$ was devoted to other program staff activities. This was mostly personnel time spent on the development of BCC materials, and the design of VCT services. Finally, 4 percent $(\$ 1,261)$ was spent on purchasing equipment for the VCT center. The details on start-up phase resources can be found in Table 1 in Appendix 1.

\section{Service Delivery}

Resources used for service delivery over the 18-month period from October 2003-March 2005 were valued at $\$ 93,228$ (see Table 2 in Appendix 1). The largest part of these resources were directly related to running the VCT unit (33 percent). Costs related to the running of the VCT unit were mainly from three different sources (partner expenses, Secretary of Health, and Population Council). Although some of the items (such as condoms) were donated, their actual costs have been added to the calculations. There are three categories of costs within this group; IEC (campaigns, materials, etc.), supplies (condoms, testing supplies, medication, etc.), and other expenses (utilities, printing, incidentals, etc.). In addition to the costs related to the running of the VCT unit, the time of the service providers required 25 percent of the resources during the service delivery phase. Finally, the rental of the trailer used for the VCT unit required 14 percent of the service delivery phase resources. Together these resources, which are directly linked to service provision, account for 73 percent of the resources used during the service delivery phase.

The activities of the program staff during the service delivery phase account for 15 percent of the service delivery resources. This was primarily the time spent by program staff on developing partnerships and engaging in ongoing public relations activities to assure the success of the intervention. Other supervisory and administrative activities also used a fair amount of program staff time. The remaining 12 percent of service delivery phase resources were used for monitoring and supervision visits by the program staff from April 2004-March 2005.

\section{Estimated Annual Cost of Service Delivery}

To calculate the annual cost of service delivery, all expenses incurred in the 18-month period were summed and average expenses were calculated. Once the resource flows were adjusted in this manner, the annual resource requirements for service delivery were estimated at $\$ 61,284$. The majority of resources would still be directly linked to service provision, but the portion used for monitoring and supervision visits would increase to 19 percent while the portion for VCT unit resources would decrease to 29 percent. Table 10 provides a summary of these results by broad category. 


\section{Hgrizons}

Table 10 Estimated annual cost of service delivery

\begin{tabular}{lrc}
\hline & \multicolumn{2}{c}{ Total } \\
\hline Other program staff activities & 8,896 & US \\
Capital goods [Trailer rental] & 8,406 & 14 \\
Service providers' time & 14,832 & 24 \\
VCT unit & 17,599 & 29 \\
Monitoring and supervision visits & 11,551 & 19 \\
TOTAL & $\mathbf{6 1 , 2 8 4}$ & $\mathbf{1 0 1}$ \\
\hline
\end{tabular}

\section{Overall Costs and Costs per Trucker Reached}

The total resources (the calculated total cost) used to implement and support the intervention for 18 months was $\$ 122,914$ (\$6,828 per month). If one considers only the expenses for service delivery, the monthly cost is $\$ 5,179$ but the actual expenditures incurred by the project were lower because some materials were donated or purchased at reduced price.

In return for this investment, 1,492 persons received comprehensive VCT services (pre-test counseling, HIV and syphilis tests, and post-test counseling), 93 received treatment for STIs using syndromic management, 5,489 truckers participated in educational activities, individually or in groups, and a great proportion of truckers entering the customs station received free condoms and IEC materials at least once. (More than 35,000 condoms were distributed, which translates to two condoms per contact.) In addition, the trailer offered free blood pressure and blood sugar measurement on demand, but the data on these activities were not registered.

Considering only the service delivery period and only the number of truckers receiving VCT $(\mathrm{n}=1,492)$, the cost for each trucker to receive pre-test counseling, the test, and post-test counseling was calculated at $\$ 62$. This does not take into account the truckers reached by other services, which would lower the costs per trucker reached. If the measure of output includes the additional 105 customs staff that received VCT, and all truckers receiving pre-test counseling even if they did not receive post-test counseling ( $\mathrm{n}=1,945$ truckers), the cost per person reached is $\$ 45$. Again, this estimate does not include those only receiving educational materials, blood pressure exams, or blood sugar measurement, or only participating in educational sessions.

\section{Estimated Cost of Replication}

Replicating the intervention is expected to require fewer resources since the BCC materials are already available and the VCT services have been designed. In addition, staff from the VCT unit would be able to serve as trainers for the next cohort of service providers rather than relying on external consultants. Under these assumptions, replicating the intervention in another site is estimated to require $\$ 22,612$ of resources during the start-up phase, a reduction of 24 percent from the original intervention (see Table 11). To this, an additional $\$ 61,284$ for service delivery (assuming the same magnitude of activities) would need to be added to get the total costs of replication for a 12-month period of service delivery. 
Table 11 Estimated cost of replication for the start-up phase

\begin{tabular}{lrc}
\hline & \multicolumn{2}{c}{ Total } \\
\hline Preparatory meetings & US\$ & $\%$ \\
Other program staff activities & 12,428 & 55 \\
Training costs & 857 & 4 \\
$\quad$ Training-1 & & \\
$\quad$ Training-2 & 5,766 & 26 \\
Capital goods [Purchased] & 2,300 & 10 \\
TOTAL & 1,261 & 6 \\
\hline
\end{tabular}




\section{Hgrizons}

\section{Discussion}

The intervention successfully reached truckers with health promotion services, particularly voluntary counseling and testing for HIV and syphilis. Among a systematic sample of truckers who passed through the customs station over a four-month period, over half (54 percent) reported participating in some of the intervention activities. Truckers who participated in the intervention reported that they liked it because it was welcoming, accessible, clean, non-stigmatizing, and helpful to have varied health services in one holistic package. Formative research had highlighted that truckers were very concerned about HIV-related stigma and truckers being identified as vectors of sexually transmitted infections. Given participants' high level of satisfaction with the services and general lack of concern about being stigmatized as a result of participation, this more holistic intervention, offering both HIV-focused services and non-HIV focused services, seems to have succeeded in addressing truckers' fears and subsequent reluctance to attend HIV/STI-focused programs. It is relevant to point out, however, that a few Brazilian truckers-all of whom had not actually used the services-still expressed concern during follow-up data collection that any HIV prevention messages targeted specifically for truckers could further stigmatize them.

Prior to this intervention, less than half of the interviewed truckers had ever been tested for HIV. These results are consistent with other Brazilian studies with truckers (Malta et al. 2006; BEMFAM, 2006), who reported that 42 percent of the truckers had ever been tested for HIV, and 45 percent of them were tested only once. The intervention increased both the proportion of truckers tested and their knowledge of places performing the test free of charge. Offering a variety of services appeared to improve use of VCT as well, since many of the truckers seeking non-HIV related services ended up participating in HIV/STI educational discussions.

In addition, the proportion of truckers who returned for their test results and post-test counseling was quite high (over 80 percent), especially considering the mobile nature of their profession. Truckers receiving VCT at the customs station in Foz do Iguaçu were as likely to return for test results as the permanent population in Foz do Iguaçu at their local reference center (Personal communication of the Director of the AIDS service in Foz do Iguaçu based on service statistics). Estimates of post-test return rates in U.S. urban settings (Keenan and Keenan 2001) and in developing country research and routine clinic settings (Coovadia 2000) are far lower.

Results indicate that the intervention was largely successful in moving truckers toward HIV risk reduction behavior change. There were clear increases in reported communication surrounding safer sex behaviors with a range of sexual partners, a common intermediate step towards sexual behavior change (Singhal and Rogers 2003; Noar et al. 2006), in the intervention community but not in the comparison community. Truckers in the intervention community spoke to their last commercial, occasional, and regular partners about condom use, getting an HIV test, and/or about STIs significantly more than truckers in the comparison community. Of particular note is the increased communication with regular partners, as condom use at baseline was low, and truckers had expressed in the formative research that it was difficult to talk about these issues with their wives/regular partners. As in this study, a quantitative and qualitative study conducted with truck drivers in Uberlândia (a city and transit hub in the southeast region of Brazil) demonstrated low frequency of condom use among truckers with their regular partners, as well as reported difficulties talking to these partners about condom use (BEMFAM 2006). Given the perceived barriers to condom use with regular partners, the reported increase in communication among truckers and their partners represents an important step toward behavior change. 
Truckers in the intervention site also reported significantly increased condom use with occasional partners, although not with commercial sex partners, where the baseline rates of condom use in both the intervention and comparison sites were already very high. Condom use increased non-significantly with primary or regular partners in both sites, but usage rates remained low overall. Because of the welldocumented difficulties inherent in changing condom use behaviors between primary partners (O'Leary 2000; Pulerwitz et al. 2002; Harvey and Henderson 2006), it is not surprising that condom use with these partners changed very little. Truckers in the intervention site, as opposed to the comparison site, also reported significantly fewer concurrent sexual partners over the past six months, another important risk reduction behavior. While the intervention focused most intensively on promoting condom use with sexual partners, the counseling and educational materials also discussed risk reduction via partner reduction, and the intervention may have had an impact in that area as well.

This project was initiated because of concerns that truckers were especially likely to engage in behaviors that lead to HIV/STI risk, and that truckers passing through the border areas had limited or no access to health services in general and HIV/STI prevention services in particular. Findings from the baseline survey demonstrated that the increased mobility of truckers, and psychosocial factors related to being on the road, were associated with increased risk behaviors. Yet, HIV prevalence was very low among truckers who sought testing. Further, while the documented prevalence of syphilis was higher than what has been reported in potentially low-risk populations in Brazil (e.g., blood bank donors), it was lower than previous estimates in Brazilian truckers (Lacerda et al. 1997) and substantially lower than estimates in other populations who may be particularly vulnerable, such as men who have sex with men. These unexpectedly low prevalence findings could indicate that the truckers seeking VCT were not representative of the whole trucker population. However, the HIV prevalence findings from this study are similar to data collected independently by the Municipal HIV/AIDS Program in Uruguaiana, which found an HIV prevalence of 0.7 percent among truckers tested between November 2001 and May 2005 (personal communication 2006). Additionally, the sociodemographic and occupational profile of the truckers who participated in the VCT intervention were similar to the non-participants and to the overall systematic sample of truckers. Given the similarities between testing and non-testing groups, these findings suggest that the prevalence of HIV in truckers may truly be equivalent to that of the general population, and the syphilis prevalence may indicate only moderately enhanced vulnerability.

The cost per person reached was found to be \$45. It is important to keep in mind that the full cost of the comprehensive program is being loaded on the output measure of persons receiving comprehensive VCT services. This cost could be significantly reduced taking other services received (e.g., outreach education, free condoms, blood pressure measurement) and other truckers reached into account. Mapping costs to these specific clients was beyond the scope of this analysis. The cost per trucker reached could also be reduced by increasing the number of truckers being tested for HIV. Because the services included some activities justified only by the research objectives of the project (for example, the administration of behavioral surveys), the VCT services required more time per client than they would have otherwise. Reports from service providers indicated that some truckers were discouraged from participation because of the length of time required and/or the sensitive topics covered by the surveys. Thus, more participants could have been recruited if the program were solely an intervention and not also part of a broader research effort. In addition, the calculated cost for replication of services in other settings was found to be substantially lower given that much of the preparation has been done and the materials have already been developed.

During the final year of the project, the intervention and research team was very focused on creating links with other institutions that could promote the sustainability of the intervention. Ministry of Health 


\section{Hgrizons}

officials and program managers from the State and Municipal Secretaries of Health repeatedly indicated that this service should be maintained after the end of the research project. To pursue potential collaborations, a number of meetings between the study staff and authorities from the three governmental levels (federal, state, and municipal) were held to discuss possible mechanisms for sustainability. Unfortunately, neither the municipal nor the state HIV programs were able to support the costs of the service after the end of the project. In response, the project team negotiated with the University of the Americas in Foz do Iguaçu to transfer the management of the health post to them; the University made a commitment to maintain the post and to add additional health services. EADI Sul also committed to the continued provision of water and electricity for the health post, and to regularly clean the health post facilities.

There were various challenges experienced during the project as well as limitations of the research. Some truckers visited both the intervention and control sites during the course of the study (14 percent of those interviewed in the comparison site participated in activities at the intervention site), which led to some cross-contamination and may have reduced the difference in the impact found by comparing truckers in the intervention community to those in the comparison community. In addition, there were some similar intervention activities implemented in the comparison site during the course of the study that could have reduced the comparative impact of the intervention. Specifically, the Municipal STI/AIDS Program in Uruguaiana also began to implement limited and sporadic VCT services with truck drivers.

Also, the populations at each site demonstrated differences in some key characteristics and outcome variables at baseline, including condom use with occasional partners, complicating direct comparisons between the populations. However, in the case of condom use with occasional partners, while the comparison site started with higher reporting of consistent use at baseline, the significantly greater percent change found from baseline to follow-up in the intervention site versus the comparison site is a strong indicator that the project was successful. Finally, some aspects of the intervention were not implemented as intensively as had originally been expected. In particular, the behavior change campaign, focused on condom use promotion, was cut short due to the intervention partner (DKT) unexpectedly losing funding. Implementation at the intended level of intensity may have led to more substantial behavior change.

The lessons learned about reaching truckers can also be applied to other mobile populations. A promising strategy for future interventions with mobile populations would include facilitating access to services and providing holistic health programs that meet more of the population's general health needs; holistic programs can help reduce potential barriers to access resulting from feared HIV stigma.

In conclusion, the strategy utilized-placing HIV/STI services in the customs station and combining them with additional health services that meet the general health needs of truckers-was successful for reaching truckers, was an acceptable strategy, and was effective in promoting some behavior change. However, given the low HIV and moderate STI prevalence, truckers in southern Brazil should not be prioritized for targeted HIV/STI programs. Truckers have a number of special health needs due to their mobility and the demands of their job; drivers should be reached with HIV and STI prevention programs as any population should, but ensuring the provision of more general health services to truckers would be the recommended intervention strategy. 


\section{References}

BEMFAM. 2006. Caminhoneiros Parcerias do asfalto. Conhecimentos, atitudes e práticas sobre o HIV/Aids em Uberlândia. Rio de Janeiro: BEMFAM.

Bharat, S., Aggleton, P.J. \& Tyrer, P. 2001. India: HIV and AIDS related discrimination, stigmatization and denial. Geneva: UNAIDS.

Bryan, A.D., J.D. Fisher, and T.J. Benziger. 2001. "Determinants of HIV risk among Indian truck drivers,” Social Science and Medicine 53: 1413-1426.

Bwayo, J., et al. 1994. "Human immunodeficiency virus infection in long-distance truck drivers in East Africa,” Archives Internal Medicine 154: 1391-1396.

Coovadia, H.M. 2000. "Access to voluntary counseling and testing for HIV in developing countries," Annals of the New York Academy of Sciences 918: 57-63.

Díaz, J., et al. 2003. A Aids Nas Fronteiras do Brasil. Brasília: Ministério da Saúde, Coordenação Nacional de DST/Aids.

Gibney, L., N. Saquib, and J. Metzger. 2003. "Behavioral risk factors for STD/HIV transmission in Bangladesh’s trucking industry,” Social Science and Medicine 56: 1411-1424.

Harvey, S.M. and J.T. Henderson. 2006. "Correlates of condom use intentions and behaviors among a community-based sample of Latino men in Los Angeles,” Journal of Urban Health 83(4): 558-74.

Keenan, P.A. and J.M. Keenan. 2001. "Rapid HIV testing in urban outreach: a strategy for improving posttest counseling rates,” AIDS Education and Prevention 13(6): 541-550.

Lacerda, R., et al. 1997. "Truck drivers in Brazil: Prevalence of HIV and other sexually transmitted diseases, risk behavior and potential for spread of infection,” AIDS 11: S15-S19.

Lagarde, E., et al. 2003. "Mobility and the spread of human immunodeficiency virus into rural areas of West Africa,” International Journal of Epidemiology 32(5): 744-752.

Lippman, S., et al. 2007. "Chaos, co-existence, and the potential for collective action: HIV-related vulnerability in Brazil’s international borders,” Social Science and Medicine, in press.

Lippman, S.A., et al. Under review. "Mobility and its liminal context: exploring sexual partnering among truck drivers crossing the Southern Brazilian border,” Social Science and Medicine.

Lurie, M.N., et al. 2003. "The impact of migration on HIV-1 transmission in South Africa: a study of migrant and nonmigrant men and their partners,” Sexually Transmitted Diseases 30(2): 149-56.

Lydié, N., et al. 2004. "Mobility, sexual behavior, and HIV infection in an urban population in Cameroon,” Acquired Immune Deficiency Syndrome 34(1): 67-73. 


\section{Hgrizons}

Madden, M.J., P.S. Ellen, and I. Ajzen. 1992. "A comparison of the theory of planned behavioral and the theory of reasoned action,” Personality and Social Psychology Bulletin 18 (1): 3-9.

Malta, M., et al. 2006. “A qualitative assessment of long distance truck drivers' vulnerability to HIV/AIDS in Itajai, southern Brazil,” AIDS Care 18(5): 489-96.

McGrath J.W., \& Ankrah E.M. 1993. “AIDS and the urban family: Its impact in Kampala, Uganda.” AIDS Care 5(1): 55-79.

McLeroy, K., et al. 1988. “An ecological perspective on health promotion programs,” Health Education Quarterly 15(4): 351-377.

Ministério da Saúde/Coordenação Nacional de DST e Aids. 2000. "Bela vista e horizonte: estudos comportamentais e epidemiológicos entre homens que fazem sexo com homens," Série Avaliação, n5. Brasília: Ministério da Saúde/Coordenação Nacional de DST e Aids.

Morris, M., et al. 1996. "Bridge populations in the spread of HIV/AIDS in Thailand,” AIDS 10: 12651271.

Municipal Program for HIV/AIDS of Uruguaiana. 2006. Personal communication.

Noar, S., K. Carlyle, and C. Cole. 2006. "Why communication is crucial: meta-analysis of the relationship between safer sexual communication and condom use,” Journal of Health Communication 11: 365-390.

Nunn, A.J. et al. 1995. "Migration and HIV-1 seroprevalence in a rural Ugandan population,” AIDS 9(5): 503-6.

Nyblade, LC. "Measuring HIV stigma: existing knowledge and gaps” Psychol Health Med. 2006

Aug;11(3):335-45.

O’Leary, A. 2000. "Women at risk for HIV from a primary partner: balancing risk and intimacy,” Annual Review of Sex Research 11: 191-234.

Plummer M.L., Mshana G., Wamoyi J., Shigongo Z.S., Hayes R.G., Ross D.A., \& Wight D. 2006. “"The man who believed he had AIDS was cured': AIDS and sexually-transmitted infection treatment-seeking behaviour in rural Mwanza, Tanzania.” AIDS Care18 (5): 4060-66.

Podhisita, C., et al. 1996. "Multiple sexual partners and condom use among long-distance truck drivers in Thailand,” AIDS Education and Prevention 8(6): 490-98.

Programa Nacional de DST/Aids, 2007. Aconselhamento em DST/HIV/Aids para a Atenção Básica. http://www.aids.gov.br/data/documents/storedDocuments/manual_simplificado.pdf

Pulerwitz, J., et al. Under review. "HIV-related stigma, service utilization and status disclosure among truck drivers crossing the Southern borders in Brazil,” AIDS Care.

Pulerwitz, J., et al. 2002. "Relationship power, condom use and HIV risk among women in the USA," AIDS Care 14(6): 789-800. 
Rao, K.S., et al. 1999. "Sexual lifestyle of long distance lorry drivers in India: questionnaire survey,” British Medical Journal 318: 162-3.

Rakwar, J., et al. 1999. "Cofactors for the acquisition of HIV-1 among heterosexual men: prospective cohort study of trucking company workers in Kenya,” AIDS 13: 607-614.

Rodrigues, C.S., M.D.C. Guimarães, and Grupo Nacional de Estudo sobre Sífilis Congênita. 2004. "Positividade para sífilis em puérperas: ainda um desafio para o Brasil," Revista Panamericana de Salud Pública 16(3): 168-75.

Salles, N.A., et al. 2003. "The discarding of blood units and the prevalence of infectious diseases in donors at the Pro-Blood Foundation/Blood Center of Sao Paulo, Sao Paulo, Brazil,” Revista Panamericana de Salud Pública 13(2-3): 111-6.

Singh, Y.N. and A.N. Malaviya. 1994. "Long distance truck drivers in India: HIV infection and their possible role in disseminating HIV into rural areas," International Journal of STD \& AIDS 5: 137-138.

Singhal, A., and E.M. Rogers. 2003. Combating AIDS: Communication Strategies in Action. Thousand Oaks, California: Sage Publications, Inc.

Stratford, D., et al. 2000. "Highway cowboys, old hands, and Christian truckers: risk behavior for human immunodeficiency virus infection among long-haul truckers in Florida," Social Science and Medicine 50: 737-749.

Thomas, M. 2005. “'What happens in Tenerife stays in Tenerife': Understanding women’s sexual behavior on holiday,” Culture, Health and Sexuality 7(6): 571-84.

Villarinho, L., et al. 2002. "Vulnerability to HIV and AIDS of short route truck drivers, Brazil” Revista de Saúde Pública 36(4 Supl): 61-7.

UNAIDS. 2001. “Population mobility and AIDS: UNAIDS technical update,” Best Practice Collection. Geneva: UNAIDS. 1998. AIDS and the military. Geneva: UNAIDS. 


\section{Hgrizons}

\section{Appendix 1}

Table 1 Costing analysis: Detailed costs from start-up and intervention phase

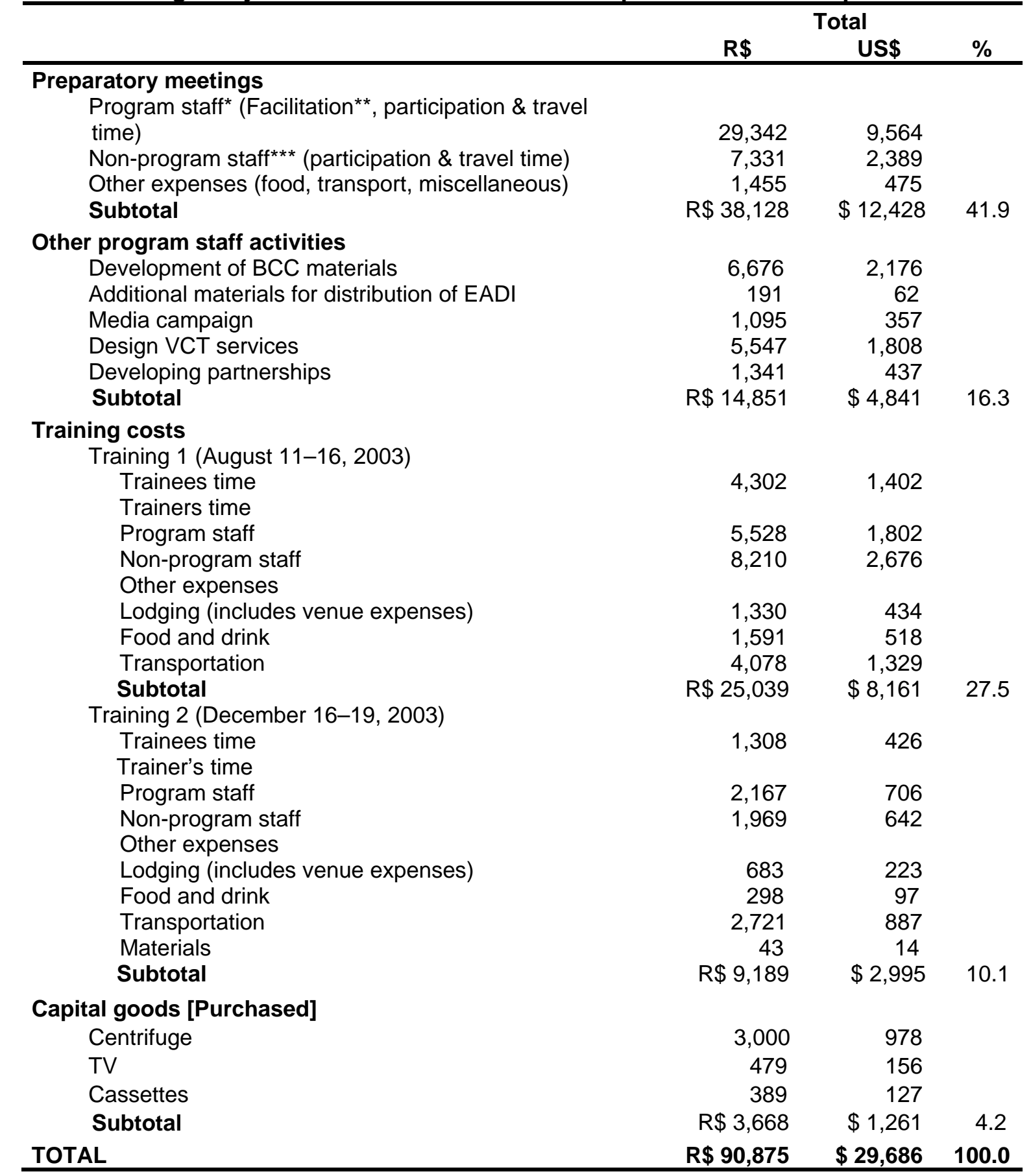

* Includes program staff associated with the intervention

** Includes participants as well as facilitators; one Population Council program staff facilitated each of these meetings

*** Includes consultants and staff from partner organizations not directly associated with the intervention 
Table 2 Service delivery phase

\begin{tabular}{|c|c|c|c|}
\hline & \multicolumn{3}{|c|}{ Total } \\
\hline & $\mathbf{R} \$$ & US\$ & $\%$ \\
\hline \multicolumn{4}{|l|}{ Other program staff activities* (19 months) } \\
\hline Implementing VCT services & 1,785 & 582 & \\
\hline Developing partnerships/public relations & 14,519 & 4,732 & \\
\hline Supervision activities & 18,036 & 5,879 & \\
\hline Administrative activities & 8,874 & 2,892 & \\
\hline Subtotal & $\mathrm{R} \$ 43,214$ & $\$ 14,085$ & $15.1 \%$ \\
\hline \multicolumn{4}{|l|}{ Capital goods [Rented] (19 months) } \\
\hline Trailer & $\mathrm{R} \$ 40,835$ & $\$ 13,310$ & $14.3 \%$ \\
\hline \multicolumn{4}{|l|}{ Service provider's time (19 months) } \\
\hline Counselors $\times 4$ & 34,055 & 11,100 & \\
\hline Nurses $\times 2$ & 16,566 & 5,400 & \\
\hline Educators $\times 2$ & 19,631 & 6,398 & \\
\hline Secretary x 1 & 1,800 & 587 & \\
\hline Subtotal & $\mathrm{R} \$ 72,052$ & $\$ 23,484$ & $25.2 \%$ \\
\hline \multicolumn{4}{|l|}{ VCT unit (21 months) } \\
\hline \multicolumn{4}{|l|}{ IEC materials } \\
\hline Campaign materials & 7,980 & 2,601 & \\
\hline \multicolumn{4}{|l|}{ Supplies } \\
\hline Condoms & 33,068 & 10,778 & \\
\hline HIV testing & 16,443 & 5,359 & \\
\hline Syphilis testing & 7,036 & 2,293 & \\
\hline Medication for syndromic management & 2,035 & 663 & \\
\hline Testing supplies (tubes, gloves, etc.) & 5,448 & 1,776 & \\
\hline \multicolumn{4}{|l|}{ Other } \\
\hline Utilities & 10,110 & 3,295 & \\
\hline Printing and photocopying & 5,228 & 1,704 & \\
\hline Lodging (travel-not meeting or training) & 320 & 104 & \\
\hline Food and drink & 52 & 17 & \\
\hline Communication (phone, post, fax, etc.) & 3,890 & 1,268 & \\
\hline Storage and transport of samples to lab. & 63 & 20 & \\
\hline Office computer supplies & 1,321 & 431 & \\
\hline Miscellaneous & 1,497 & 488 & \\
\hline Subtotal & $\mathrm{R} \$ 99,491$ & $\$ 30,798$ & $33.0 \%$ \\
\hline Monitoring and supervision visits (12 months) & $\mathrm{R} \$ 35,438$ & $\$ 11,551$ & $12.4 \%$ \\
\hline TOTAL & $\mathrm{R} \$ 291,030$ & $\$ 93,228$ & $100.0 \%$ \\
\hline
\end{tabular}

*Includes program staff associated with the intervention 


\section{Hgrizons}

\section{Appendix 2}

\section{Educational Brochure}

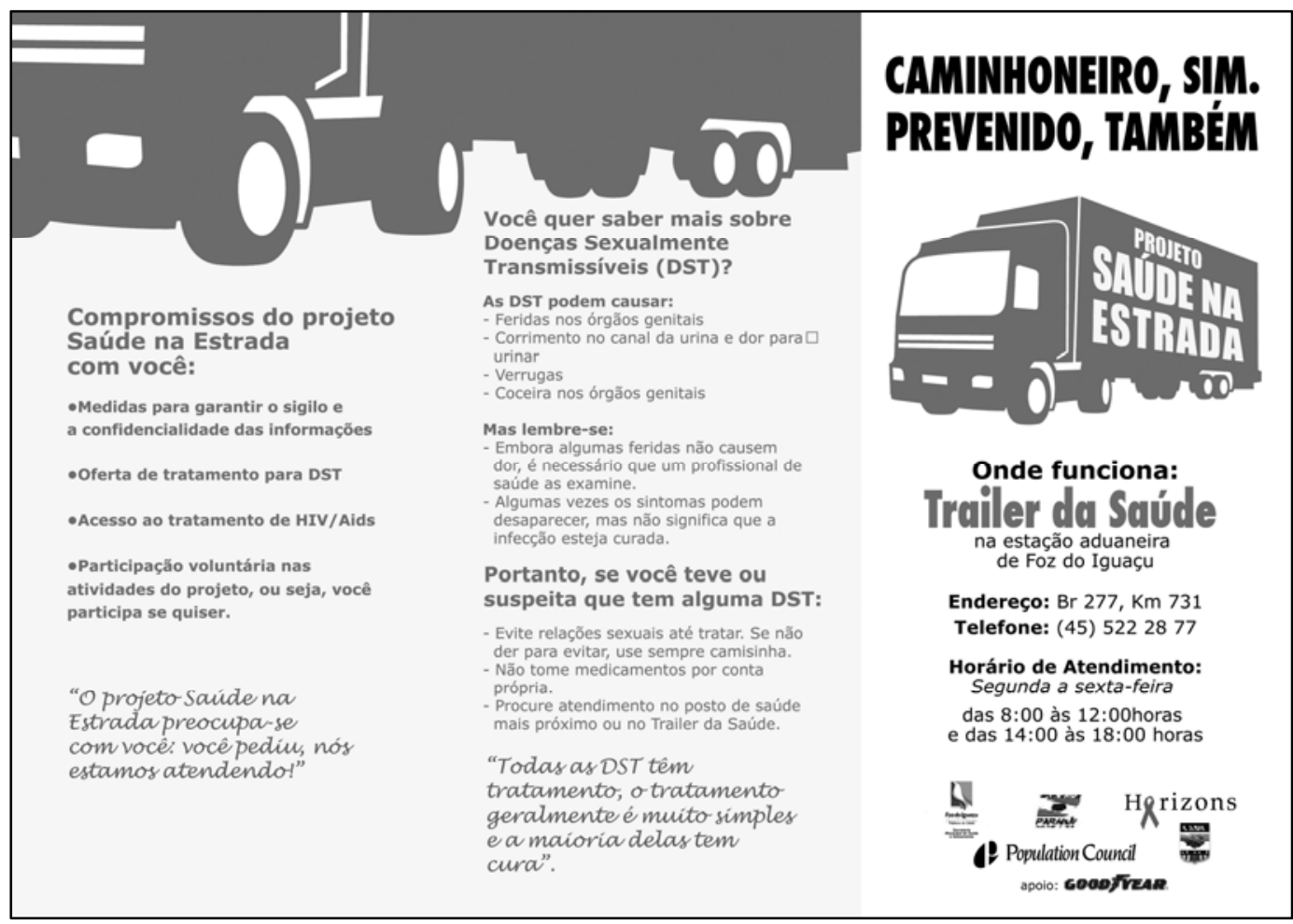

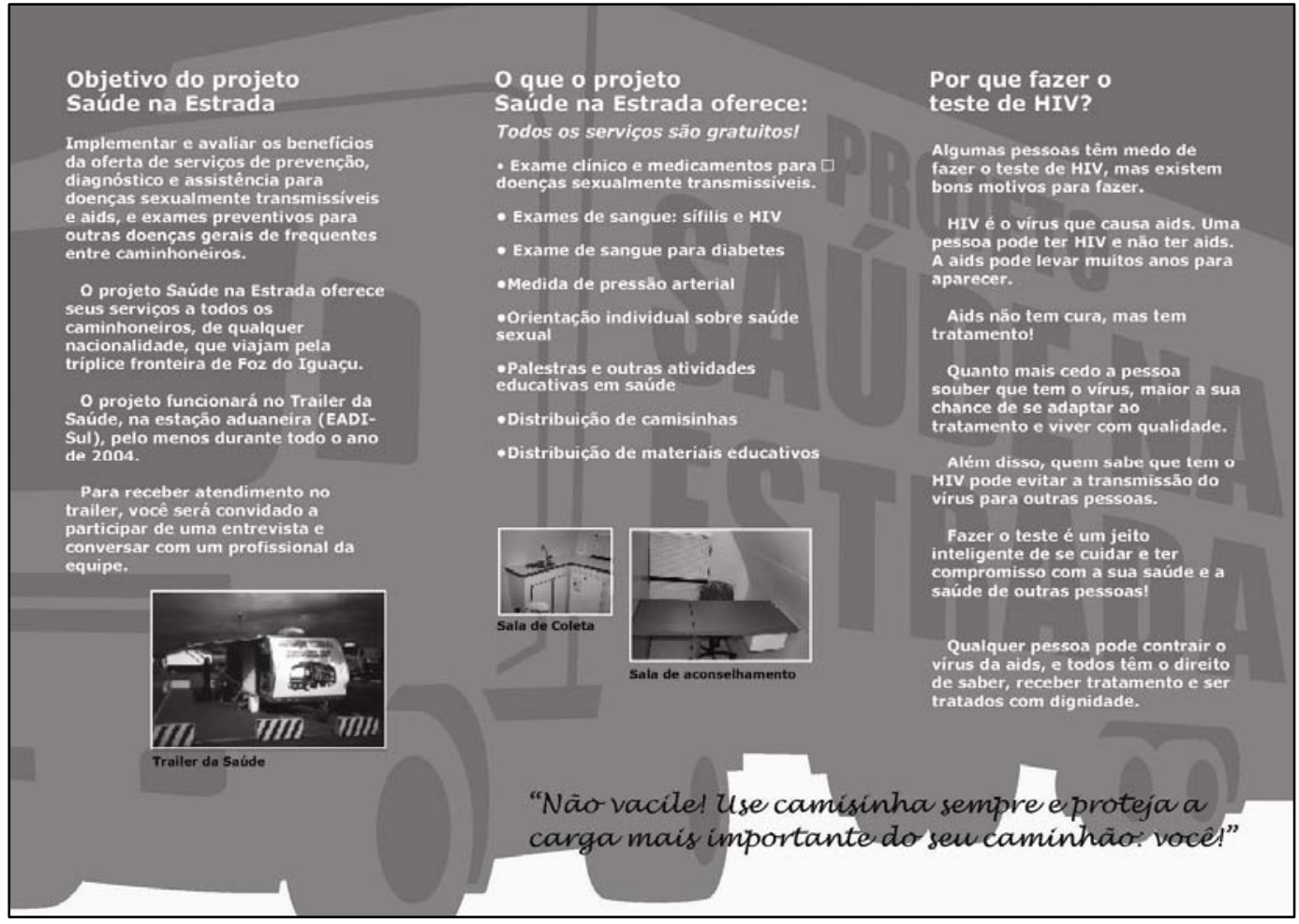




\section{Hgrizons}

Horizons is a global operations research program designed to:

- Identify and test potential strategies to improve HIV/AIDS prevention, care, and support programs and service delivery.

- Disseminate best practices and utilize findings with a view toward scaling up successful interventions.

\section{(2) Population Council}

Horizons is implemented by the Population Council in collaboration with

- International Center for Research on Women (ICRW)

- International HIV/AIDS Alliance

- PATH

- Tulane University

- Family Health International (FHI)

- Johns Hopkins University

For more information, please contact:

Horizons Program, Communications Unit 4301 Connecticut Avenue, NW Suite 280 Washington, DC 20008 USA

Tel: 202-237-9400

Fax: 202-237-8410

Email: horizons@pcdc.org www.popcouncil.org/horizons 